\title{
The Theory of Ice Nucleation by Heterogeneous Freezing of Deliquescent Mixed CCN. Part I: Critical Radius, Energy, and Nucleation Rate
}

\author{
VitALY I. KHVOROSTYANOV \\ Central Aerological Observatory, Moscow, Russia \\ JUDITH A. CURRY \\ School of Earth and Atmospheric Sciences, Georgia Institute of Technology, Atlanta, Georgia
}

(Manuscript received 15 July 2002, in final form 26 March 2004)

\begin{abstract}
This paper extends previous work on the theory of heterogenous ice nucleation. The goals of this analysis are to explain empirical observations of ice nucleation and to provide a suitable framework for modeling and parameterizing the ice nucleation process in cloud-scale and large-scale atmospheric models. Considered are the processes of heterogeneous freezing of deliquescent mixed cloud condensation nuclei that may serve as ice nuclei, and the properties of an ice germ critical radius, energy, and nucleation rate of ice crystals are examined as functions of temperature and supersaturation. Expressions for nucleation in a polydisperse aerosol for the deliquescence-freezing mode are developed. Equations are derived for the threshold and critical saturation ratios as functions of temperature and nucleation rate, and for the threshold and critical temperatures as functions of saturation ratio. Equivalence of the new formulation for the freezing point depression with traditional expressions is shown and the concepts of the effective temperature and supercooling are introduced. These new formulations are used in a companion paper for simulations of ice nucleation using a cloud parcel model.
\end{abstract}

\section{Introduction}

One of the greatest challenges to understanding and predicting the evolution of clouds is nucleation of the ice phase. This understanding and prediction is important for determining the earth's radiation budget and the atmospheric hydrological cycle. Since homogeneous ice nucleation (formation of ice particles in supercooled drops without presence of a foreign substrate) becomes effective for the cloud drops at temperatures lower than $-38^{\circ} \mathrm{C}$, it has usually been assumed that ice clouds in the atmosphere at temperatures warmer than $-38^{\circ} \mathrm{C}$ form via heterogeneous nucleation, that is, with participation of the foreign substrate (Pruppacher and Klett 1997, hereafter PK97). Heterogeneous nucleation also is active at temperatures colder than $-38^{\circ} \mathrm{C}$, although the relative magnitude of heterogeneous and homogeneous nucleation at these colder temperatures is not known. Our specific motivation for investigating heterogeneous ice nucleation is in the context of polar clouds, which are frequently observed to be mixed phase (e.g., Curry et al. 1996), and also deep convective clouds and anvil cirrus, when large amounts of mixed aerosol

Corresponding author address: Dr. J. A. Curry, School of Earth and Atmospheric Sciences, Georgia Institute of Technology, Atlanta, GA 30332-0340.

E-mail: curryja@eas.gatech.edu particles can be brought into the middle and upper troposphere and may serve as ice nuclei (e.g., DeMott 2002).

For the past four decades, ice nucleation processes and the number concentration $N_{\mathrm{IN}}$ of atmospheric aerosol particles that initiate ice phase [ice nuclei (IN)], have been parameterized as two independent functions of temperature (Fletcher 1962) and of supersaturation over ice or over water (e.g., Huffman 1973; Meyers et al. 1992; see PK97 and Young 1993 for a review). There have been several attempts at representation of experimentally derived values of IN concentration simultaneously as a function of temperature and supersaturation (e.g., Berezinsky and Stepanov 1986; Cotton et al. 1986). Fukuta and Schaller (1982) developed a theory of condensation freezing that proceeds in two steps: (a) condensation on the surface of insoluble nucleus at water supersaturation, and (b) subsequent freezing of the formed water film. Both processes are calculated using classical heterogeneous freezing theory following Fletcher's (1962) formulation. This work was probably first to combine theoretically the temperature and supersaturation dependencies in heterogeneous ice nucleation. A similar model was suggested by Young (1993) for the immersion-freezing mode. This approach can be suitable for description of heterogeneous ice nucleation on insoluble IN at water supersaturation, in particular on artificial IN used in cloud seeding. 
In the real atmosphere, most ice nuclei have appreciable fractions of soluble materials (e.g., Young 1993), which has been emphasized in recent field projects [e.g., Subsonic Aircraft: Contrail and Cloud Effects Special Study (SUCCESS), spring 1996; and First International Satellite Cloud Climatology Project (ISCCP) Regional Experiment (FIRE) Surface Heat Budget of the Arctic (SHEBA) spring-summer 1998]. Specifically, detailed analysis of IN physicochemical properties showed that IN are not necessarily totally insoluble (Chen et al. 1998), but rather a significant fraction of the IN are characterized by mixtures of insoluble substrates with sulfates or other soluble materials with the soluble volume fractions of $0.2-0.9$. Hence the same aerosol particles may serve both as IN and cloud condensation nuclei $(\mathrm{CCN})$, the fraction of these mixed IN was up to $40 \%$ of the IN in the lower and middle troposphere and up to $27 \%$ in the upper troposphere (Chen et al. 1998; Rogers et al. 1998, 2001). Note that the energy-dispersive X-ray analysis used in these experiments was not able to detect soluble mass fractions smaller than $10 \%$; if it had been possible to lower this threshold (e.g., down to $1 \%$ ), the fractions of these mixed IN-CCN could be considerably higher. For example, a mixed $\mathrm{CCN}$ of radius of $0.1 \mu \mathrm{m}$ with $\mathrm{NaCl}$ as soluble substance with mass fractions only of $\chi_{m} \approx 0.08$ and 0.008 can be activated into a droplet at supersaturations $0.18 \%$ and $0.52 \%$, respectively (Hänel 1976; Table 6.3 in PK97). Thus, such particles may serve as CCN at sufficiently high supersaturations (updrafts), but could be identified as insoluble IN in these measurements.

These experiments indicate the necessity of modifying the traditional view of IN as completely insoluble particles, as well as the parameterizations of heterogeneous ice nucleation. DeMott et al. (1998), based on observations of Chen et al. (1998), DeMott et al. (1998), and Rogers et al. (1998), developed a model of heterogeneous ice nucleation [hereafter, a model of Colorado State University (CSU)] by assuming that all heterogeneous IN are freezing nuclei, which are deliquescent mixed CCN with 50\% insoluble and 50\% soluble matter (sulfuric acid in the upper troposphere), and are contained within $10 \%$ of the CCN population with sizes above $0.1 \mu \mathrm{m}$; the freezing fraction of these IN-CCN was parameterized as a function of temperature. Using classical nucleation theory, Khvorostyanov and Curry (2000, hereafter KC00) developed a theory of heterogeneous ice nucleation by freezing of the $\mathrm{CCN}$ containing both soluble and insoluble fractions, with the possibility of ice nucleation both at water sub- and supersaturations.

DeMott (2002) recently formulated a comprehensive scheme of ice nucleation processes that includes both homogeneous and heterogeneous freezing with detailed pathways within each mode and among them. The homogeneous freezing of solution drops (fully soluble deliquescent $\mathrm{CCN}$ or haze particles) occurs without an in- soluble substrate at temperatures less than $-40^{\circ} \mathrm{C}$, and condensation freezing is defined by DeMott (2002) as heterogeneous freezing of solution droplets, which implies that the soluble component of a mixed CCN causes condensation and the insoluble component catalyses ice nucleation. A new concept of ice nucleation was suggested recently by Djikaev et al. (2002) and Tabazadeh et al. (2002): pseudoheterogeneous (or surface stimulated) crystallization of the drops that may initiate at the liquid-air interface at temperatures both colder and warmer than $-38^{\circ} \mathrm{C}$ and proceed without involving foreign ice nuclei. However, a theory of this phenomenon has not been developed.

It has been assumed in many studies that the dominant mode of crystal formation in cold cirrus is homogeneous freezing of haze particles in conditions of subsaturation with respect to water (e.g., Sassen and Dodd 1988, 1989; Heymsfield and Sabin 1989; DeMott et al. 1994). An important and possibly dominant role of heterogeneous freezing in cirrus and contrail formation in slow updrafts has been recognized recently (e.g., DeMott et al. 1994, 1997, 1998; Jensen et al. 1994; Kärcher et al. 1996; Sassen and Benson 2000; Lin et al. 2002). In a recent international Cirrus Parcel Model Comparison Project (CPMCP) with seven participating groups (Lin et al. 2002), four models account for heterogeneous ice nucleation inside haze particles at water subsaturation in a manner similar to the model of CSU by DeMott et al. (1998) described above.

A theory of heterogeneous ice nucleation developed in KC00 and extended in this paper is also conceptually very close to the heterogeneous nucleation treatment of DeMott et al. (1998). Here we generalize the concept of homogeneous freezing of fully soluble $\mathrm{CCN}$ to the case of mixed $\mathrm{CCN}$ freezing, extending the concept to temperatures as high as a few degrees below $0^{\circ} \mathrm{C}$. Equations for the critical radius and activation energy show that nucleation becomes possible due to the catalyzing effect of insoluble substrate within CCN that counteracts the freezing point depression by the solution effect, significantly lowering the energy barrier for freezing and permitting freezing at smaller supercooling than that for homogeneous freezing. These equations show that ice nucleation may occur with noticeable and significant rate on the surface of the insoluble substance embedded in a solution drop that has formed on a dry CCN. Therefore, the basic premises of this theory are as follows: (a) the same deliquescent hygroscopic aerosol (haze particles) that serves as CCN may serve also as IN under freezing conditions; (b) in contrast to homogeneous nucleation case, these haze particles contain an insoluble substrate (which is typical of $\mathrm{CCN}$ ); (c) in contrast to drop activation, where the soluble fraction determines the activity of a nucleus, heterogeneous ice nucleation is determined also by the insoluble fraction of $\mathrm{CCN}$, which is a nucleation catalyzer; (d) heterogeneous ice nucleation may occur on these 
CCN-IN; it will be shown that this process may take place both at water supersaturations and subsaturations (but above the deliquescent threshold of the soluble fraction).

While the process described here shares some common features with the concept of condensation freezing described by Vali (1985) and Fukuta and Schaller (1982), our theory permits ice nucleation under conditions of subsaturation with respect to liquid water, whereby deliquescence of mixed $\mathrm{CCN}$ can form an ice particle at supercooled temperatures. Hence we adopt the term "deliquescent-heterogeneous freezing" (DHF) of mixed CCN. Our treatment of the DHF mode is different from the condensation-freezing theory of Fukuta and Schaller (1982), since we do not consider condensation on insoluble IN followed by freezing as in that work, but consider ice germ formation on the insoluble substance within a drop formed on a natural mixed (partially hygroscopic) CCN, similar to DeMott et al. (1998). The IN from the DHF mode may comprise only a fraction of $\mathrm{CCN}$ aerosol particles that may freeze under certain conditions. It is known that typical CCN concentration $N_{\mathrm{CCN}} \sim 10^{5}-10^{6} \mathrm{~L}^{-1}$, while typical $N_{\text {IN }} \sim 1-100 \mathrm{~L}^{-1}$. However, it will be shown in a companion paper (Khvorostyanov and Curry 2005, hereafter Part II) that only a tiny fraction of CCN $\left(10^{-6}\right.$ to $10^{-3}$ ) can be nucleated as ice crystals, because there is a very strong dependence of critical radius and activation energy on the relative humidity that decreases after the initial nucleation events, preventing further nucleation. It will be shown that this hypothesis is in agreement with many experimental data including the temperature and supersaturation dependencies of the ice nuclei concentrations.

This two-part paper extends and applies the work of KC00. Part I is devoted to general studies of the properties of the critical radius and activation energy and nucleation rate for heterogeneous nucleation by freezing of deliquescent $\mathrm{CCN}$. We derive analytical dependence of the critical energy and nucleation rate on supersaturation, along with analytical expressions for threshold and critical saturation ratios as functions of temperature, and for the threshold and critical temperatures as functions of saturation ratio. We examine nucleation in a polydisperse aerosol, and temperature and humidity dependence of the aerosol size range with maximum contribution to nucleation rate. Equivalence of the new formulation for the freezing point depression with the traditional expression is shown based on the concepts of the effective temperature and supercooling. In Part II, this theory of heterogeneous nucleation is applied in a dynamical cloud parcel model with explicit bin microphysics for numerical simulation of ice crystal formation under various initial conditions and vertical velocities. The relative importance of heterogeneous versus homogeneous nucleation is examined under these various conditions.

\section{A model of ice nucleation by freezing of deliquescent $\mathrm{CCN}$ and cloud drops}

We consider a three-phase system consisting of an ice germ of radius $r_{\mathrm{cr}}$ that forms on a curved insoluble substrate with radius $r_{N}$ inside an aqueous solution drop with radius $r_{d}$. The ice germ is in equilibrium with the drop, which itself is in equilibrium with the environmental moist air, these conditions define the critical ice germ radius $r_{\text {cr }}$.

The rate of heterogeneous germ formation in a supercooled droplet of water or solution, $J_{s, \mathrm{fr}}\left[\mathrm{s}^{-1}\right.$ particle $^{-1}$ ], can be calculated following PK97 as

$$
\begin{aligned}
J_{s, \mathrm{fr}}\left(T, r_{N}\right)=C_{\mathrm{het}} \exp [ & \left.-\frac{\Delta F_{\mathrm{act}}}{k T}-\frac{\Delta F_{\mathrm{cr}}}{k T}\right], \\
C_{\text {het }} & \approx \frac{k T}{h} c_{1 s} 4 \pi r_{N}^{2},
\end{aligned}
$$

where $k$ and $h$ are Boltzmann's and Planck's constants, $T$ is temperature in kelvins, $\Delta F_{\text {act }}$ is the activation energy at the solution-ice interface, $\Delta F_{\text {cr }}$ is the critical energy of germ formation, $C_{\text {het }}$ is the normalizing function, $r_{N}$ the radius of an insoluble fraction of an aerosol particle (IN), and $c_{1, S}$ is the concentration of water molecules adsorbed on $1 \mathrm{~cm}^{-2}$ of a surface. According to Fletcher (1962) and Young (1993), $c_{1, S} \sim 10^{15} \mathrm{~cm}^{-2}$ and $C_{\text {het }} \sim$ $10^{28} r_{N}^{2}$. Fletcher (1962, p. 45) emphasized that variation of $C_{\text {het }}$ even by a few orders of magnitude has little effect of the final result because of the primary effect of the exponential term on the nucleation rates.

Application of (2.1) for calculation of the nucleation rate $J_{s, f r}$ requires knowledge of the critical energy $\Delta F_{\text {cr }}$ that is related to the ice germ critical radius $r_{\mathrm{cr}}$. In this section, we derive the equations for $\Delta F_{\mathrm{cr}}$ and $r_{\mathrm{cr}}$. This development follows that outlined briefly by $\mathrm{KC} 00$, but including more detailed analysis of various processes and assumptions.

\section{a. Critical radius}

The entropy equation for this system at equilibrium is generalized from Dufour and Defay (1963), Defay et al. (1966), and PK97 [Eq. (6-57)] to be

$$
\begin{gathered}
-\frac{L_{m}(T)}{T} d T+\left(\frac{2}{\rho_{w}}-\frac{2}{\rho_{i}}\right) d\left(\frac{\sigma_{s a}}{r_{d}}\right)-\frac{2}{\rho_{i}} d\left(\frac{\sigma_{i s}}{r_{c r}}\right)-d\left(\frac{C_{\varepsilon} \varepsilon^{2}}{\rho_{i}}\right) \\
+\frac{R T}{M_{w}} d \ln a_{w}=0 .
\end{gathered}
$$

Here, $L_{m}$ is the latent heat of melting, $\rho_{i}$ and $\rho_{w}$ the ice and water densities, $\sigma_{\mathrm{sa}}$ and $\sigma_{\mathrm{is}}$ are the surface tensions at the solution-air and solution-ice interfaces, $M_{w}$ is the molecular weight of water, $a_{w}$ is the activity of water in solution and $R$ is the universal gas constant.

The fourth term on the right-hand side of (2.2) (not included by PK97 in the general derivation, but dis- 
cussed in chapter 9) is associated with the elastic strain $\varepsilon$ produced in the ice embryo by the insoluble substrate, and $C_{\varepsilon} \sim 1.7 \times 10^{11} \mathrm{dyn}_{\mathrm{cm}^{-2}}$ (Turnbull and Vonnegut 1952). The effect of this term is to increase the activation energy and decrease the nucleation rate, thereby shifting the nucleation curves to colder temperatures (PK97; Young 1993). If the crystal lattice of the insoluble substrate satisfies the condition of epitaxy, that is, has hexagonal structure with the parameters close to ice, then $\varepsilon$ can be $\sim 1 \%-5 \%$, and if the substrate lattice is dissimilar to ice, then the germ lattice is not accommodated to it and $\varepsilon=0$ (Fletcher 1962; Young 1993). We have included this term in (2.1), since upon integration it yields expressions for $r_{\mathrm{cr}}, \Delta F_{\mathrm{cr}}$ similar to those in Fletcher (1962) and Young (1993) (see appendix B).

To derive an expression for the critical radius of an ice germ $r_{\text {cr }}$, we can integrate (2.2) with the usual boundary conditions $a_{w}=1, r_{\text {cr }}=\infty, r_{d}=\infty$ at the triple point $T=T_{0}=273.15 \mathrm{~K}$. In addition, since the ice lattice tends to the structure of liquid water at $T \rightarrow T_{0}$, the misfit increases, the condition of epitaxy is not satisfied then, and we can assume $\varepsilon=0$ at $T=T_{0}$ as discussed above. Using also the definition for $a_{w}$ in solution containing a solid insoluble substance (PK97), we obtain after integration and some algebraic transformations

$$
L_{m}^{\mathrm{ef}}(T) \ln \frac{T_{0}}{T}-\frac{C_{\varepsilon} \varepsilon^{2}}{\rho_{i}}=\frac{2}{\rho_{i}}\left(\frac{\sigma_{\mathrm{sa}}}{r_{d}}+\frac{\sigma_{\mathrm{is}}}{r_{\mathrm{cr}}}\right)-\frac{R T}{M_{w}} H_{\mathrm{sc}} .
$$

Here, $L_{m}^{\mathrm{ef}}=\int_{T}^{T_{0}}\left[L_{m}(T) / T\right] d T / \ln \left(T_{0} / T\right)$ is the effective average latent heat of melting that can be evaluated using a polynomial fit for $L_{m}(T)$ (PK97), and we have denoted

$$
\begin{gathered}
H_{\mathrm{cs}}=\frac{A_{\mathrm{sa}}}{r_{d}}-\frac{B_{\mathrm{sa}}}{\left(r_{d}^{3}-r_{d 0}^{3}\right)}, \quad A_{\mathrm{sa}}=\frac{2 \sigma_{\mathrm{sa}} M_{w}}{\rho_{w} R T}, \\
B_{\mathrm{sa}}=\frac{\nu \Phi_{s} \chi_{m} M_{w} \rho_{d 0} r_{d 0}^{3}}{M_{s} \rho_{w}},
\end{gathered}
$$

where $\Phi_{s}$ is the osmotic coefficient, $\nu$ is the number of ions in solution, $\chi_{m}$ and $M_{s}$ are the mass fraction and the molecular weight of soluble material of a nucleus, $r_{d 0}$ and $\rho_{d 0}$ are the radius and density of an original dry $\mathrm{CCN}$ before deliquescence that can be evaluated as the weighted values between soluble and insoluble fractions with the weight $\chi_{m}$ (PK97). In (2.4), $A_{\mathrm{sa}}$ is Kelvin's curvature parameter for the air-solution interface, and $B_{\text {sa }}$ describes the solution effects. From (2.3), we obtain $r_{\mathrm{cr}}$ :

$$
r_{\mathrm{cr}}=\frac{2 \sigma_{\mathrm{is}}}{\rho_{i} L_{m}^{\mathrm{ef}}(T) \ln \left(\frac{T_{0}}{T}\right)+\frac{R T \rho_{i}}{M_{w}} H_{\mathrm{cs}}-C_{\varepsilon} \varepsilon^{2}-\frac{2 \sigma_{\mathrm{sa}}}{r_{d}}} .
$$

This equation describes an ice germ that may form in- side both nonactivated $\mathrm{CCN}$ and a cloud drop, and can be simplified for a deliquescent CCN. Note first that if the saturation ratio with respect to liquid water $S_{w}$ increases in an air parcel, the following three cases may occur: 1) freezing of deliquescent $\mathrm{CCN}$ at subsaturated conditions relative to water $S_{w}<1$; 2) activation of cloud drops at the condensation stage at $S_{w} \geq 1$ and their subsequent freezing; or 3) freezing at $S_{w}>1$ of residual interstitial $\mathrm{CCN}$ that are left after drop formation (mostly at cloud temperatures $-10^{\circ}$ to $-20^{\circ} \mathrm{C}$, see Part II). Processes 1 and 3 correspond to the deliquescence-freezing (or condensation freezing) mode and process 2 corresponds to immersion-freezing mode.

The deliquescent CCN in cases 1 and 3 obey the Kohler equation, which relates $S_{w}$ to the droplet curvature and solution concentration (e.g., PK97):

$$
\ln S_{w}=\frac{A_{\mathrm{sa}}}{r_{d}}-\frac{B_{\mathrm{sa}}}{\left(r_{d}^{3}-r_{d 0}^{3}\right)}=H_{\mathrm{cs}} .
$$

Using (2.6), (2.5) for the ice germ radius can be simplified:

$$
r_{\mathrm{cr}}=\frac{2 \sigma_{\mathrm{is}}}{\rho_{i} L_{m}^{\mathrm{ef}}(T) \ln \left(\frac{T_{0}}{T} S_{w}^{G}\right)-C_{\varepsilon} \varepsilon^{2}-\frac{r_{\mathrm{sc}}}{r_{d}}},
$$

where we have introduced a new dimensionless parameter $G(T)$, and a scaling radius $r_{\mathrm{sc}}$ :

$$
G(T)=\frac{R T}{M_{w} L_{m}^{\mathrm{ef}}}, \quad r_{\mathrm{sc}}=\frac{2 \sigma_{\mathrm{sa}}}{\rho_{i} L_{m}^{\mathrm{ef}}} .
$$

For drops with $r_{d} \gg r_{\text {sc }}$, it is easily shown that the term $r_{\mathrm{sc}} / r_{d}$ in (2.7) can be neglected.

In case 2 (immersion mode for activated drops), (2.6) is not valid for drops growing in the field of external supersaturation, (2.5) cannot be reduced to (2.7), and we have to use (2.5) for $r_{\mathrm{cr}}$. In this case, the curvature and solution effects are known to be relatively small for drops with radius of a few microns.

\section{b. Separation of insoluble fraction between activated drops and unactivated CCN}

During drop activation, separation (or redistribution) of insoluble fraction occurs between activated drops and unactivated $\mathrm{CCN}$. The soluble substance of $\mathrm{CCN}$ before activation can be characterized by the mass fraction $\chi_{m}$, and so the insoluble fraction is $\chi_{N}=1-\chi_{m}$. The critical saturation ratio (or supersaturation $\delta_{w, \mathrm{cr}}$ ) for a drop activation depends on the CCN dry radius $r_{d 0}$ and its soluble fraction $\chi_{m}$ (e.g., PK97). For any given $r_{d 0}$, critical saturation ratio increases with decreasing $\chi_{m}$. So, when the maximum saturation ratio $S_{w, \max }$ is reached in a cooling cloud parcel during drop activation, all CCN of the same radius $r_{d 0}$ with $\chi_{m}>\chi_{m, \text { cr }}$ will be activated, and all with $\chi_{m}<\chi_{m, \text { cr }}\left(\chi_{N}>\chi_{N, \text { cr }}\right)$ will remain as deliquescent CCN (e.g., Hänel 1976). This leads to the natural separation of the insoluble substance: its fraction 
$\chi_{N}$ will be substantially greater in these nonactivated $\mathrm{CCN}$ than in the cloud drops, and the insoluble fraction in unactivated CCN increases with increasing $r_{d 0}$. Note also that the radius of the dry particle $r_{d 0}$ and its insoluble fraction $r_{N}$ are related as $r_{N} \sim r_{d 0} \chi_{N}^{1 / 3}$, so that $r_{N}$ grows with increasing $r_{d 0}$ at constant $\chi_{N}$, which may explain the higher ice nucleating activity of the larger CCN.

Since the heterogeneous nucleation rate is $J_{s, \mathrm{fr}} \sim r_{N}^{2}$, this accumulation of the insoluble substrate in deliquescent interstitial CCN will increase their integral surface area and ice nucleating ability relative to the activated drops. Thus, separation of insoluble fraction during drop activation may explain several effects in ice nucleation if these interstitial CCN serve as IN: (a) higher insolubility of these particles as compared to the average CCN; (b) higher ice nucleating efficiency of larger $\mathrm{CCN}$ that contain larger amounts of insoluble material; (c) higher efficiency of the CCN freezing mode than that of the immersion mode; and (d) higher efficiency of the contact mode compared to the immersion mode if these interstitial CCN collide with the drops and serve as contact nuclei. Note that the dilution $m_{w} / m_{d}$ of these $\mathrm{CCN}$, with $m_{w}$ being the mass of accumulated water, is high enough even for small soluble fraction, and salt concentration is low at saturation ratios close to critical (PK97, Tables 6.2 and 6.3). Thus the solution freezing point depression is small, and the catalyzing freezing action of insoluble substrate can overwhelm the effects of the freezing point depression.

A quantitative description of this separation and subsequent heterogeneous ice nucleation requires knowledge of the $\mathrm{CCN}$ distributions by dry radii and insoluble (or soluble) fraction. Unfortunately, information on the distribution of insoluble fraction among $\mathrm{CCN}$ of the same size is very scarce, since typical measurements of the soluble fraction cover some size range but not single particles (PK97). Thus we can only hypothesize a plausible size distribution function of these interstitial deliquescent aerosols.

\section{c. Characteristic times of relaxation of $C C N$ size and solution concentration}

The characteristic times of CCN size and the solution concentration relaxation illuminate the mechanism for the impact of supersaturation on an ice germ. It is known that the radius of a deliquescent $\mathrm{CCN}$ adjusts to equilibrium as predicted by the Kohler curves (2.6). Otherwise, supersaturation or subsaturation $\delta_{w}=S_{w}-1$ occurs around a CCN droplet and it grows or evaporates until its radius $r_{d}$ reaches such a value that the equilibrium condition in (2.6) is satisfied. The relaxation time $\tau_{\text {eq }}$ during which deliquescent $\mathrm{CCN}$ reach equilibrium both at sub- and supersaturation can be estimated following Sedunov (1974) as $\tau_{\text {eq }} \approx 0.4 \times 10^{6} r_{d}^{2} /\left|S_{w}-1\right|$ in seconds with $r_{d}$ in centimeters. Both deliquescent $\mathrm{CCN}$ at $S_{w}<1$ and interstitial $\mathrm{CCN}$ at $S_{w}>1$ reach equilibrium very rapidly (generally much less than in 1 s) in response to variations of external supersaturation.

An additional time scale $\tau_{\text {dif }}$ characterizes the time during which salt concentration within a CCN drop reaches equilibrium due to the diffusion processes and becomes homogeneous. It can be estimated (Sedunov 1974) as $\tau_{\mathrm{dif}} \sim 0.14 r_{d}^{2} / D_{c}$, where $D_{c} \sim 10^{-5} \mathrm{~cm}^{2} \mathrm{~s}^{-1}$ is the coefficient of mass (salt) diffusion within a drop. This yields an estimate $\tau_{\text {dif }} \sim 10^{-6} \mathrm{~s}$ and $10^{-4} \mathrm{~s}$ for drops of radii 0.1 and $1 \mu \mathrm{m}$, respectively. The characteristic time of mean supersaturation variations $\tau_{\text {sup }}$ in natural clouds without vigorous updrafts is typically $10^{2}-10^{3} \mathrm{~s}$, so that the hierarchy of the time scales is $\tau_{\text {sup }}$ $\gg \tau_{\text {eq }} \geq \tau_{\text {dif }}$; that is, $\tau_{\text {sup }}$ is much greater than both $\tau_{\text {eq }}$ and $\tau_{\text {dif }}$.

These estimations illustrate the main mechanism by which variations of external supersaturation $\delta_{w}$ influence an ice germ that is embedded in a solution drop and is not in direct contact with external supersaturation field: variations of supersaturation are immediately followed by the much faster adjustment of the $\mathrm{CCN}$ size and homogenization of solution concentration in the entire drop volume including vicinity of the insoluble substrate and ice germ. The growth of the saturation ratio $S_{w}$ (or $\left.\delta_{w}\right)$ is accompanied by the rapid swelling of a deliquescent $\mathrm{CCN}$ and decrease in solution concentration, which decreases $r_{\text {cr }}\left(T, S_{w}\right)$ as described by (2.7). Vice versa, a decrease of $S_{w}$ is followed by the shrinking of a $\mathrm{CCN}$, increase in solution concentration and growth of $r_{\mathrm{cr}}\left(T, S_{w}\right)$. Thereby the link is established between varying $S_{w}$ (or $\delta_{w}$ ) and $r_{\text {cr }}$ inside CCN. An ice germ embedded in a CCN drop and "remote" to the external supersaturation, is nonetheless influenced by it very fast via adjustment of the drop radius to supersaturation. Note that the same mechanism of impact of $\delta_{w}$ on remote $r_{\text {cr }}$ acts in homogeneous freezing as described by the equations for $r_{\text {cr }}$ derived in Jensen et al. (1994), Tabazadeh et al. (1997), and Khvorostyanov and Sassen (1998a, 2002).

The characteristic freezing time $\tau_{\mathrm{fr}}$ under conditions considered in this paper is typically a few tens to hundreds of seconds (Part II), thus $\tau_{\text {fr }} \gg \tau_{\text {eq }}$, and $\tau_{\text {fr }} \gg \tau_{\text {dif }}$, and this rapid adjustment of $r_{\mathrm{cr}}$ to varying supersaturation occurs also during $\mathrm{CCN}$ freezing. Various particular cases of (2.7) and their comparison with the other models are considered in appendix B. For drops of a few microns, the impact of supersaturation on $r_{\mathrm{cr}}$ and freezing point depression should be much smaller because of the smaller contribution of the term $H_{\mathrm{cs}}$ in denominator of (2.5).

\section{d. Critical energy and freezing nucleation rate}

The critical energy $\Delta F_{\text {cr }}$ of a germ formation in (2.1) can be expressed as

$$
\Delta F_{\mathrm{cr}}=\frac{4}{3} \pi \sigma_{\mathrm{is}} r_{\mathrm{cr}}^{2} f\left(m_{\mathrm{is}}, x\right)-\alpha r_{N}^{2}\left(1-m_{\mathrm{is}}\right) .
$$


The expression for $\Delta F_{\text {cr }}$ in (2.9) is generalized following Fletcher (1969) to account for the "active sites" with relative area $\alpha$, so that an IN (insoluble substrate) of radius $r_{N}$ contains a patch of area $\alpha r_{N}^{2}$ with $m_{\text {is }}=1$, and the rest of the surface is characterized by $m_{\mathrm{is}}<1$. For the DHF mode with $r_{\text {cr }}$ from (2.7), (2.9) can be rewritten

$$
\begin{aligned}
\Delta F_{\mathrm{cr}}= & \frac{(16 \pi / 3) \sigma_{\mathrm{is}}^{3} f\left(m_{\mathrm{is}}, x\right)}{\left[\rho_{i} L_{m}^{\mathrm{ef}} \ln \left(\frac{T_{0}}{T} S_{w}^{G}\right)-C \varepsilon^{2}-\frac{r_{\mathrm{sc}}}{r_{d}}\right]^{2}} \\
& -\alpha r_{N}^{2}\left(1-m_{\mathrm{is}}\right) .
\end{aligned}
$$

In the immersion mode, (2.9) for $\Delta F_{\text {cr }}$ should be used with $r_{\text {cr }}$ defined by (2.5) and (2.4).

The geometric factor $f\left(m_{\mathrm{is}}, x\right)$ in (2.9) and (2.10) arises from the geometry of the spherical cap and an aerosol particle with radius $r_{N}$. This factor can be expressed (following Fletcher 1962) via the ratio $x=r_{N} / r_{\text {cr }}$ and the contact or wettability parameter (cosine of the contact angle $\theta_{\text {is }}$ at the solution-ice interface), $m_{\text {is }}=$ $\cos \theta_{\text {is }}=\left[\left(\sigma_{N s}-\sigma_{N i}\right) / \sigma_{i s}\right]$, where $\sigma_{N s}$ and $\sigma_{N i}$ are the surface tensions at the solution-substrate and ice-substrate interfaces:

$$
\begin{array}{r}
f\left(m_{\mathrm{is}}, x\right)=(1 / 2)\left\{1+\left[\left(1-m_{\mathrm{is}} x\right) / y\right]^{3}+x^{3}\left(2-3 \psi+\psi^{3}\right)\right. \\
\left.+3 m_{\mathrm{is}} x^{2}(\psi-1)\right\}, \quad \psi=\left(x-m_{\mathrm{is}}\right) / y, \\
y=\left(1-2 m_{\mathrm{is}} x+x^{2}\right)^{1 / 2}
\end{array}
$$

Consider the particular cases of small and large $r_{N}$. In the small particle limit $x=r_{N} / r_{\text {cr }} \ll 1$ (which may correspond to vanishing insoluble substrate, $r_{N} \rightarrow 0$ ), the value of contact angle $\theta_{\text {is }}=180^{\circ}, m_{\text {is }}=-1$ and $f\left(m_{\mathrm{is}}, x\right)=1$. The corresponding expressions (2.7) and (2.10) in the small particle limit for $r_{\text {cr }}$ and $\Delta F_{\text {cr }}$ with $\varepsilon$ $=0$ and $\alpha=0$ coincide with the critical radius and energy derived in Khvorostyanov and Sassen (1998a) for homogeneous nucleation; hence homogeneous nucleation can be considered to represent a particular case of heterogeneous nucleation. In the large particle limit $x=r_{N} / r_{\text {cr }} \gg 1$, the geometrical factor (2.11) reduces to its value for plane substrate, $f\left(m_{\mathrm{is}}, x\right)=\left(m_{\mathrm{is}}^{3}-3 m_{\mathrm{is}}\right.$ $+2) / 4$. It is shown below that the typical values of $r_{\text {cr }}$ $\sim 3 \times 10^{-3}$ to $10^{-2} \mu \mathrm{m}$, and the major contribution to nucleation rates, comes from the particles with $r_{N} \sim$ $0.1-1 \mu \mathrm{m}$. Thus the case with $x \gg 1$ is practically the most important. Typical values of $f\left(m_{\text {is }}=0.5\right)=0.156$ and $f\left(m_{\mathrm{is}}=0.36\right)=0.242$ characterize critical energy reduction due to cap geometry and favors heterogeneous nucleation in the large particle limit as compared to the case of homogeneous nucleation.

\section{Interpretation and evaluation of derived functional relationships \\ a. Dependence of critical radius, energy, and nucleation rate on temperature and saturation ratio}

In the calculations described here, we use the temperature and solution concentration parameterizations of

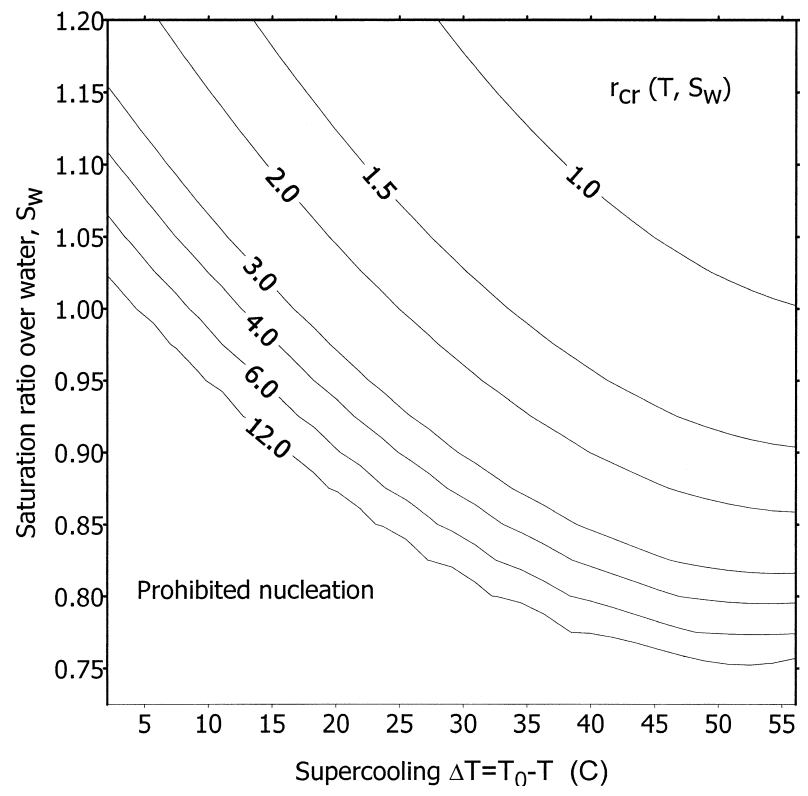

FIG. 1. Critical radius $r_{\text {cr }}\left(10^{-7} \mathrm{~cm}\right)$ for the freezing mode as a function of supercooling $\Delta T=T-T_{0}$ and saturation ratio over water $S_{w}$ (the $T-S_{w}$ diagram); $r_{\text {cr }}$ is same as for homogeneous nucleation.

$\rho_{i}, \rho_{w}, L_{m}, \sigma_{\text {sa }}, \sigma_{\text {is }}$, from PK97 and Tabazadeh et al. (1997), $\Delta F_{\text {act }}(T)$ was fitted to Jeffrey and Austin (1997), and the contact parameter is specified as $m_{\text {is }}=0.5$ for DHF mode in most calculations. Figures 1-4 present $r_{\text {cr }}$ and $\Delta F_{\text {cr }}$ calculated with (2.7) and (2.10) in two forms: as $2 \mathrm{D}$ fields on a $T-S_{w}$ diagram, and as functions of temperature for several humidities. Figure 1 shows isolines of the critical radius $r_{\mathrm{cr}}$ for the deliquescence-freezing mode on the $T-S_{w}$ diagram. Note that since $r_{\text {cr }}$ does not depend on $f\left(m_{\mathrm{is}}, x\right), r_{\mathrm{cr}}$ is same as for homogeneous nucleation as described in Khvorostyanov and Sassen (1998a, 2002) and DeMott (2002). The isolines of $r_{\text {cr }}$ extend from the lower right-hand corner to the upper left-hand corner, since the temperature increase of $50^{\circ} \mathrm{C}$ is approximately compensated by the humidity increase of $50 \%$ as described below by (3.16). Values of $r_{\mathrm{cr}}$ range from $\sim 10^{-7} \mathrm{~cm}$ at $S_{w} \sim 1.3, T \sim-55^{\circ} \mathrm{C}$ to $10^{-6} \mathrm{~cm}$ at warmer $T$ or lower $S_{w}$. Then $r_{\text {cr }}$ increases rapidly toward the left lower corner while denominator in (2.7) for $r_{\mathrm{cr}}$ goes to zero and therefore $r_{\mathrm{cr}}$ tends to infinity. Nucleation is prohibited in the left lower corner since the denominator in (2.7) and $r_{\text {cr }}$ become negative.

Figure 2 shows an order of magnitude decrease of $r_{\text {cr }}$ over the temperature range from $-3^{\circ}$ to $-10^{\circ} \mathrm{C}$ at $S_{w}$ $=1.001$, typical of conditions in a mixed-phase cloud and from $-15^{\circ}$ to $-30^{\circ} \mathrm{C}$ at $S_{w}=0.9$, typical for colder crystalline clouds or diamond dust formation. The value of $r_{\text {cr }}$ may increase with decreasing $T$ if $S_{w}$ decreases rapidly with $T$. The critical radius for deposition is greater than for deliquescene freezing for all values of $T$ at $S_{w}=0.97$.

The 2D field of the critical energy $\Delta F_{\text {cr }}$ on the $T-S_{w}$ diagram (Fig. 3) is similar to the field of $r_{\mathrm{cr}}$. Nucleation 


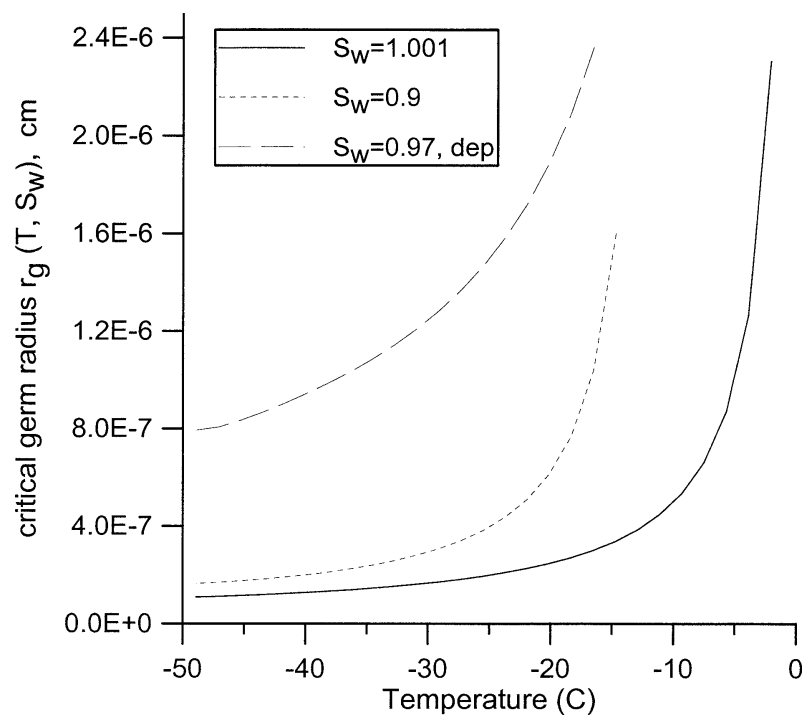

FIG. 2. Critical germ radius $r_{\mathrm{cr}}$ for the freezing mode as a function of temperature with contact parameter $m=0.5$ for the saturation ratios over water, $S_{w}=1.001$ (solid line), $S_{w}=0.9$ (short dash), and for the deposition mode with $m=0.95$ and $S_{w}=0.97$ (long dash).

is prohibited in the lower left-hand portion of the diagram because the critical radius becomes negative here (Fig. 1). The $T$ curves for $\Delta F_{\text {cr }}$ (Fig. 4) show that lowering humidity by $10 \%$ leads to a decrease in $\Delta F_{\text {cr }}$ by $0.5-1$ orders of magnitude. The critical energy of deposition is much greater than for deliquescence freezing decreasing the probability of deposition. The activation energy $\Delta F_{\text {act }}$ is smaller than $\Delta F_{\text {cr }}$ at $S_{w}=1.001$ and $S_{w}$

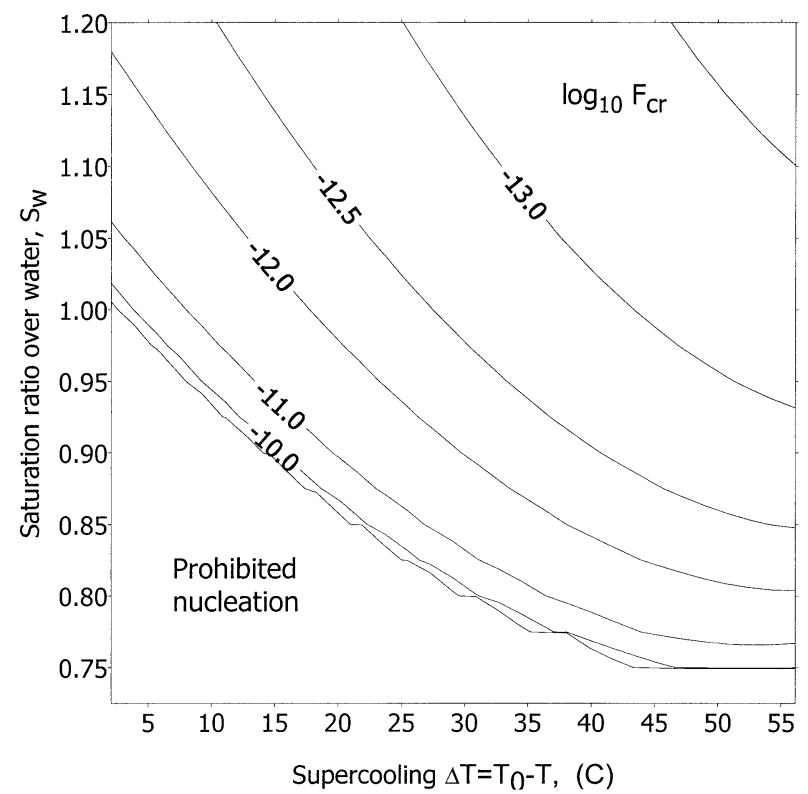

FIG. 3. Logarithm of the critical energy $F_{\text {cr }}$ (erg) for the freezing mode as a function of supercooling $\Delta T=T-T_{0}$ and saturation ratio over water $S_{w}$ calculated with contact parameter $m=0.5$ and $r_{N}=$ $0.46 \mu \mathrm{m}$.

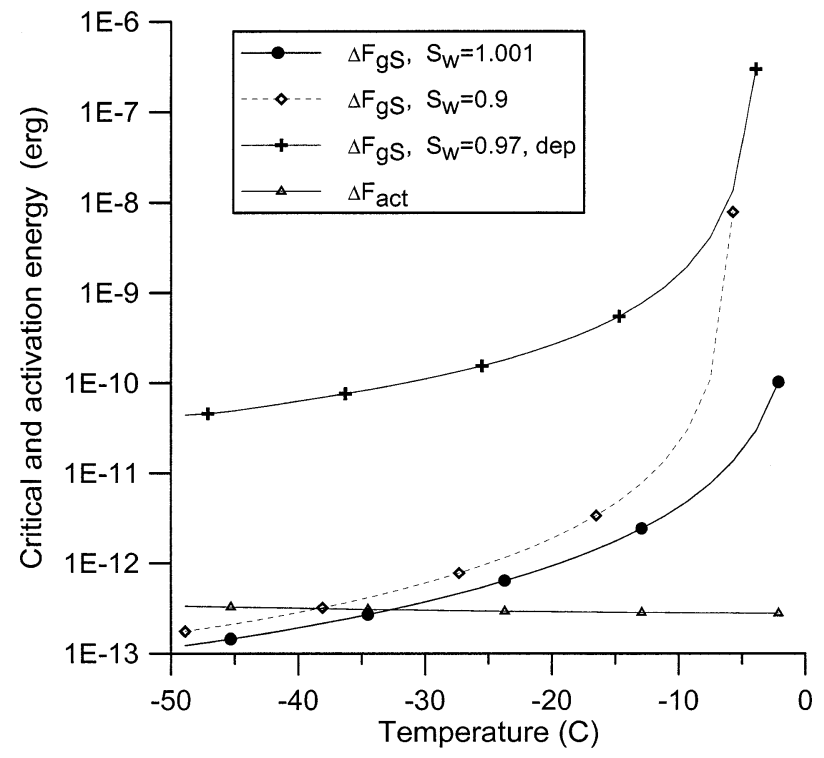

FIG. 4. Critical germ energy $F_{\text {cr }}$ for the deliquescence-freezing mode as a function of temperature with the contact parameter $m=$ 0.5 for the four saturation ratios over water, $S_{w}=1.001$ (circles), $S_{w}$ $=0.95$ (diamonds), and for the deposition mode with $m=0.95$ and $S_{w}=0.97$ (crosses). Activation energy $\Delta F_{\text {act }}$ is presented for comparison (triangles).

$=0.95$ to $T>-35^{\circ} \ldots-38^{\circ} \mathrm{C}$, and $\Delta F_{\text {act }}$ exceeds $\Delta F_{\text {cr }}$ at lower temperatures. Therefore, the role of $\Delta F_{\text {act }}$ in ice nucleation increases for very cold clouds.

Logarithm of the freezing nucleation rate per particle $J_{s, \mathrm{fr}}\left(\mathrm{s}^{-1}\right)$ is presented in Fig. 5 on the $T-S_{w}$ diagram,

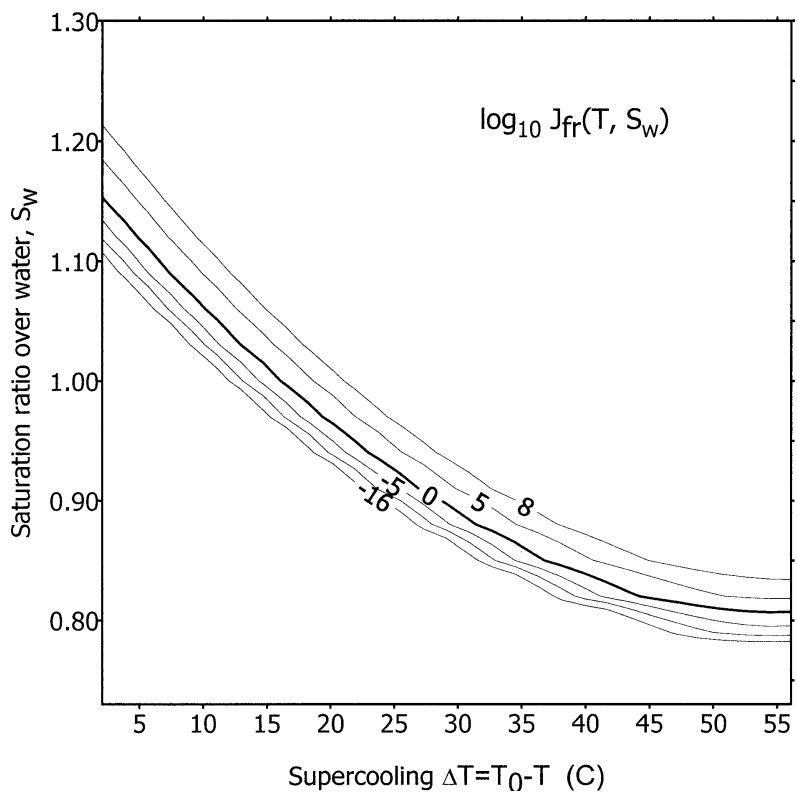

FIG. 5. Logarithm of the freezing nucleation rate $J_{\text {sfr }}\left(\mathrm{s}^{-1}\right)$ as a function of two variables: supercooling $\Delta T=T-T_{0}$ and saturation ratio over water $S_{w}$ calculated with contact parameter $m=0.5$ and $r_{N}=0.46 \mu \mathrm{m}$. The bold isoline " 0 " corresponds to the rate $J_{s, \mathrm{fr}}=$ $1 \mathrm{~s}^{-1}$. 
calculated from (2.1) using contact parameter $m_{\mathrm{is}}=0.5$ and $r_{N}=0.26 \mu \mathrm{m}$. This figure shows very high gradients of $J_{s, \mathrm{fr}}$, varying by $10-15$ orders of magnitude over the temperature range of $5^{\circ} \mathrm{C}$ or humidity range of $5 \%$. The bold isoline " 0 " corresponds to the rate $J_{s, \mathrm{fr}}=1 \mathrm{~s}^{-1}$ and indicates the values of $T$ and $S_{w}$, where the nucleation rate becomes significant. Figure 6 illustrates the temperature dependence of $J_{s, \mathrm{fr}}$ for various humidities. Even relatively small variations in humidity and its variation with $T$ lead to significant change in the nucleation rate. At typical cloud saturation ratio of 1.001 (supersaturation $0.1 \%), J_{s, \text { fr }}$ reaches values of $10^{-5}$ to $1 \mathrm{~s}^{-1}$ at $T=-13^{\circ}$ to $-15^{\circ} \mathrm{C}$. An increase in $S_{w}$ to $1.05\left(\delta_{w}=\right.$ $5 \%$ ) causes the shift to higher $T$ by $5^{\circ} \mathrm{C}$ (the reason for this is explained in section $3 \mathrm{~d}$ ), so that ice nucleation may occur with noticeable rate at $T$ about $-10^{\circ} \mathrm{C}$, in agreement with observations by Hobbs and Rangno (1990) and Rangno and Hobbs (1991) and their explanation of this effect with the hypothesis on possible cloud pockets of high supersaturation. It will be shown in Part II that increase of $m_{\text {is }}$ to $0.55-0.65$ or presence of active sites with surface fraction $\alpha \sim 2 \times 10^{-5}$ causes noticeable nucleation rates at warmer temperatures $-5^{\circ}$ to $-9^{\circ} \mathrm{C}$ at low $\delta_{w}=0.1 \%-0.2 \%$. At temperatures below $-20^{\circ} \mathrm{C}$, ice nucleation occurs at subsaturations. The nucleation rates and final crystal concentrations are discussed in more detail in Part II with the parcel model.

\section{b. Separation of the temperature and supersaturation dependences of the critical energy and nucleation rate}

The dependence of $\Delta F_{\text {cr }}$ and $J_{s, \text { fr }}$ on the supersaturation with respect to water $\left(\delta_{w}\right)$ can be isolated and determined analytically, which is useful in illustrating the functional relationships and is potentially useful for parameterizations. Using the relations $S_{w}=1+\delta_{w}$, and $\ln \left(1+\delta_{w}\right) \approx \delta_{w}$ for $\delta_{w} \ll 1$, (2.10) for $\Delta F_{\text {cr }}$ can be rewritten as (we assume for simplicity that $\alpha=0, \varepsilon=$ $\left.0, r_{d}=\infty\right)$

$$
\begin{aligned}
\Delta F_{\mathrm{cr}}\left(T, \delta_{w}\right) & =\frac{\Delta F_{\mathrm{cr}, 0}(T)}{\left[1+\frac{G \delta_{w}}{\ln \left(T_{0} / T\right)}\right]^{2}}, \\
\Delta F_{\mathrm{cr}, 0}(T) & =\frac{16 \pi}{3} \frac{\sigma_{\mathrm{is}}^{3} f\left(m_{\mathrm{is}}, x\right)}{\left[\rho_{i} L_{m}^{\mathrm{ef}} \ln \left(\frac{T_{0}}{T}\right)\right]^{2}} .
\end{aligned}
$$

Using the relation $\ln \left(T_{0} / T\right) \approx \Delta T / T$, where $\Delta T=T_{0}-$ $T$ is supercooling, and expanding the denominator in (3.1) by the power series of $X=G T \delta_{w} / \Delta T$, we obtain

$$
\Delta F_{\mathrm{cr}}\left(T, \delta_{w}\right) \approx \Delta F_{\mathrm{cr}, 0}(T)\left[1-2 G \frac{\delta_{w}}{(\Delta T / T)}\right] .
$$

Here the critical energy $\Delta F_{\mathrm{cr}}\left(T, \delta_{w}\right)$ is separated into two factors: $\Delta F_{\text {cro }}(T)$ is the critical energy at $\delta_{w}=0$ or

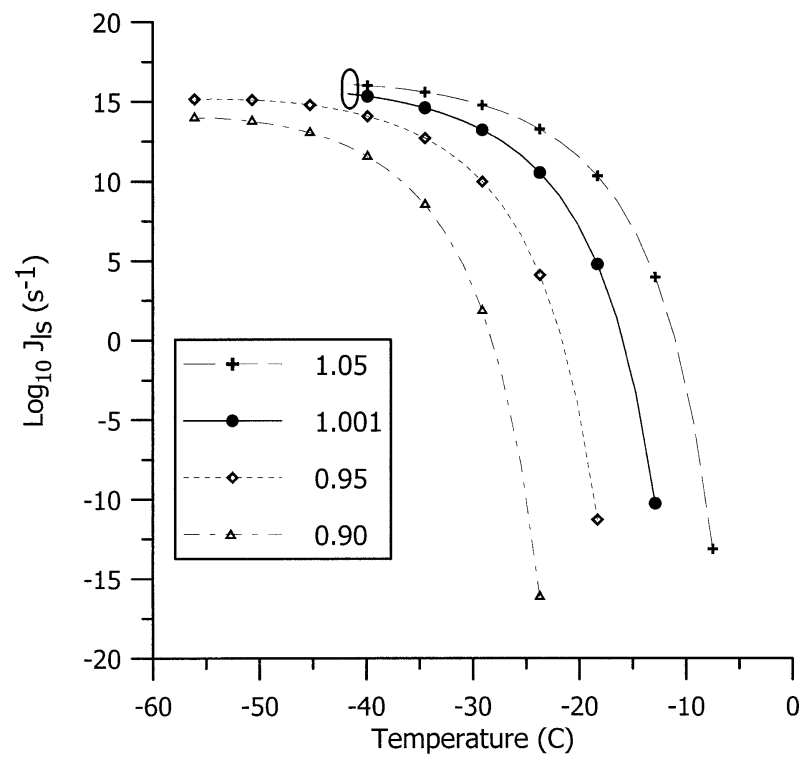

FIG. 6. Freezing nucleation rate $J_{s, \mathrm{fr}}\left(\mathrm{s}^{-1}\right)$ for the CCN freezing mode as a function of the temperature with the contact parameter $m$ $=0.5$ for the saturation ratios over water, $S_{w}=1.05$ (crosses), $S_{w}=$ 1.001 (circles), $S_{w}=0.95$ (diamonds), and $S_{w}=0.90$ (triangles). The threshold of homogeneous freezing of drops with $r_{d} \sim 0.2-5 \mu \mathrm{m}$ at $T_{c} \sim-42^{\circ} \ldots-38^{\circ} \mathrm{C}$ is denoted by an ellipse.

$\left(S_{w}=1\right)$, which depends only on $T$ [see (3.1)], and the bracketed term describes the dependence on supersaturation. The expansion by $X$ is valid under the condition $X \ll 1$, or

$$
\delta_{w} \ll \frac{\Delta T}{G T} \approx 2.5 \frac{\Delta T}{T} .
$$

Substituting (3.2) into (2.1), we obtain for $J_{s, \mathrm{fr}}$

$$
J_{s, \mathrm{fr}}\left(T, \delta_{w}\right)=J_{s, \mathrm{fr}}^{(0)}(T) \lambda\left(T, \delta_{w}\right),
$$

where again $J_{s, \text { fr }}^{(0)}(T)$ is the nucleation rate at $\delta_{w}=0$ or $S_{w}=1$. Equation (3.4) shows that the supersaturation factor $\lambda\left(T, S_{w}\right)$ can be approximated in different forms, either as a power law or as an exponential function:

$$
\begin{aligned}
\lambda\left(T, \delta_{w}\right) & =[b(T)]^{\delta_{w}}=\exp \left(C_{\delta} \delta_{w}\right), \\
b(T) & =\exp \left[\frac{\Delta F_{\mathrm{cr}, 0}(T)}{k \Delta T} 2 G(T)\right], \\
C_{\delta}(\Delta T) & =\frac{\Delta F_{\mathrm{cr}, 0}(T)}{k \Delta T} 2 G(T) .
\end{aligned}
$$

Equations (3.2)-(3.6) describe analytically the supersaturation dependence of the critical energy and nucleation rate and can be used for development of parameterizations of these quantities. Thus $\lambda\left(T, \delta_{w}\right)$ and $J_{s, \text { fr }}$ increase exponentially with $\delta_{w}$, resembling the empirical parameterizations of Meyers et al. (1992) and Rogers et al. (1998) (but with additional $T$ dependence). This exponential variation may explain very fast crystal nucleation rates in clouds at and after the stage of in- 
tensive coagulation among the drops and decrease of their concentration when supersaturation may increase above its normal value of $0.01 \%-0.1 \%$ and produce high $N_{c}$ as was hypothesized by Hobbs and Rangno (1990); Rangno and Hobbs $(1991,2001)$ and was discussed with Fig. 5. Other reasons of high $N_{c}$ are discussed in Part II.

\section{c. Critical and threshold saturation ratios}

The preceding equations allow formulation of the threshold saturation ratio $S_{w, \text { th }}(T)$ for ice nucleation by deliquescent-freezing mode, and also the critical saturation ratio $S_{w, \text { cr }}(T)$ at some prescribed $J_{s, \mathrm{fr}}$. The value of $S_{w, \text { cr }}$ can be easily derived substituting (2.7) and (2.10) for $r_{\mathrm{cr}}, \Delta F_{\text {cr }}$ into (2.1) for $J_{s, \mathrm{fr}}$, and resolving it for $S_{w}$ (we assume for simplicity $\alpha=0$ ):

$$
\begin{aligned}
S_{w, \mathrm{cr}}= & \left\{\frac{T}{T_{0}} \exp \left(\frac{C_{\varepsilon} \varepsilon^{2}}{\rho_{i} L_{m}^{\mathrm{ef}}}+\frac{r_{\mathrm{sc}}}{r_{d}}\right)\right. \\
& \left.\times \exp \left[\frac{1}{L_{m}^{\mathrm{ef}} \rho_{i}}\left(-\frac{16 \pi}{3} \frac{f\left(m_{\mathrm{is}}, x\right) \sigma_{\mathrm{is}}^{3}}{k T \ln \left(J_{s, \mathrm{fr}} / C_{\mathrm{het}}\right)+\Delta F_{\mathrm{act}}}\right)^{1 / 2}\right]\right\}^{1 / G} .
\end{aligned}
$$

Equation (3.7) describes the critical value of $S_{w, \text { cr }}$ for arbitrary nucleation rate $J_{s, \mathrm{fr}}$. It holds also for homogeneous freezing nucleation with substitution $J_{s, \mathrm{fr}} \rightarrow$ $J_{\text {hom }}, C_{\text {het }} \rightarrow C_{\text {hom }}, f=1$, and $\varepsilon=0\left(J_{\text {hom }}\right.$ and $C_{\text {hom }}$ are defined in Part II). For very slow processes, when $J_{s, \text { fr }}$ $\rightarrow 0$, that is, at the threshold of the nucleation process, $\ln J_{s, \text { fr }} \rightarrow-\infty$, (3.7) is simplified and we obtain the threshold saturation ratio

$$
S_{w, \text { th }}=\left[\frac{T}{T_{0}} \exp \left(\frac{C_{\varepsilon} \varepsilon^{2}}{\rho_{i} L_{m}^{\mathrm{ef}}}+\frac{r_{\mathrm{sc}}}{r_{d}}\right)\right]^{1 / G} .
$$

For $\varepsilon=0$ and $r_{d} \gg r_{\mathrm{sc}}$, (3.8) is further simplified

$$
S_{w, \text { th }}=\left(T / T_{0}\right)^{1 / G}=\left(T / T_{0}\right)^{M_{w} L_{m}^{\mathrm{ef}} / \mathrm{RT}} .
$$

Note that $r_{\text {cr }}$ and $S_{w, \text { th }}$ in this case are the same as for homogeneous freezing nucleation. Equations (3.8) and (3.9) coincide with the corresponding equations from KC00 and Khvorostyanov and Sassen (1998a, 2002), where they were derived from the condition $r_{\mathrm{cr}}>0$, and (3.7) generalizes these expressions for $S_{w, \text { th }}$ to the case of arbitrary nucleation rates $J_{s, \mathrm{fr}}$. Since $G=0.4-0.47$ (Table 1 in $\mathrm{KC} 00)$ at $T=268.15$ to $243.15 \mathrm{~K}\left(T=-5^{\circ}\right.$ to $\left.-30^{\circ} \mathrm{C}\right), S_{\mathrm{th}} \approx\left(T / T_{0}\right)^{2.22}$ in this temperature range; $G$ $=0.53-0.7$ and $S_{\mathrm{th}} \approx\left(T / T_{0}\right)^{1.54}$ at $T=233.15$ to $213.15 \mathrm{~K}\left(-40^{\circ}\right.$ to $\left.-60^{\circ} \mathrm{C}\right)$. The difference between $S_{w, \text { th }}$ and $S_{w, \text { cr }}$ is the following. The threshold saturation ratio represents an absolute minimum below which ice nucleation cannot occur, that is, is a necessary but still not sufficient condition for nucleation, while critical saturation ratio represents a sufficient condition, which ensures substantial nucleation rates.

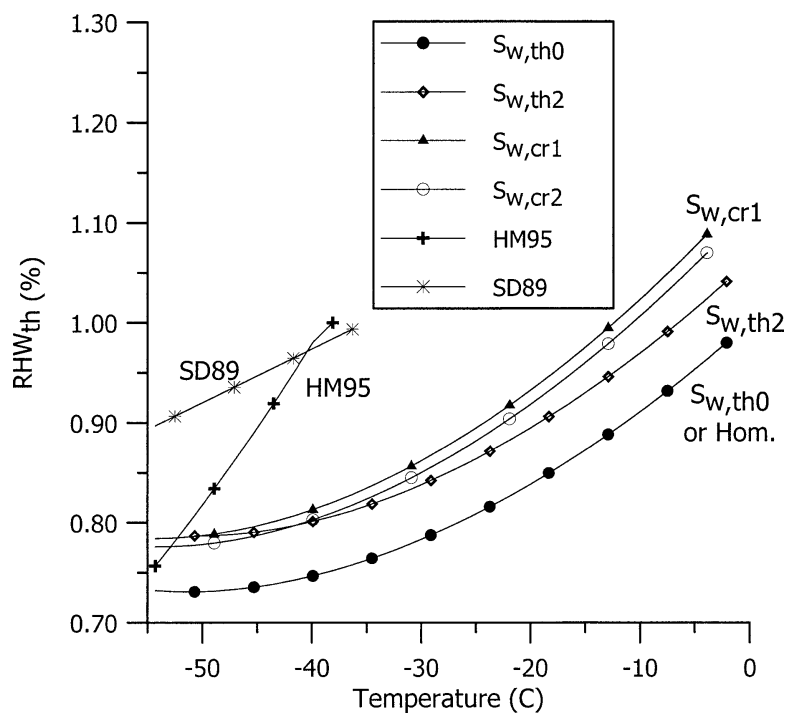

FIG. 7. Threshold saturation ratios of heterogeneous nucleation, $S_{w, \text { th }}$, for $\varepsilon=0$ (solid circles, denoted $S_{w \text {,th0 }}$; the same as for homogeneous nucleation denoted Hom), for $\varepsilon=2.0 \%$ (diamonds, $S_{w, \text { th } 2}$ ), and the critical saturation ratio $S_{w, \mathrm{cr}}(T)$ of "significant nucleation rate" calculated with $\varepsilon=0$ and the conditions $J_{s, \mathrm{fr}}=1 \mathrm{~s}^{-1}$ (triangles, $S_{w, \mathrm{crl}}$ ) and $J_{s, \mathrm{fr}}=10^{-6} \mathrm{~s}^{-1}$ (open circles, $S_{w, \mathrm{cr} 2}$ ). The curve SD89 (asterisks) is parameterization by Sassen and Dodd (1989) and HM95 (crosses) is parameterization by Heymsfield and Miloshevich (1995).

In Fig. 7, a comparison is presented between the threshold value $S_{w, \text { th }}$ defined in (3.8) and (3.9), and the critical saturation ratio $S_{w, \text { cr }}(T)$, defined in (3.7) for $J_{s, \text { fr }}$ $=1 \mathrm{~s}^{-1}$ and $10^{-5} \mathrm{~s}^{-1}$. Figure 7 shows a monotonic decrease of both saturation ratios with decreasing temperature from $\sim 1$ at $-10^{\circ} \mathrm{C}$ to $0.72-0.78$ at $-50^{\circ} \mathrm{C} ; S_{w, \text { cr }}$ at $\varepsilon=0$ is higher than $S_{w, \text { th }}$ by $\sim 0.1$ at $-10^{\circ} \mathrm{C}$ and by $\sim 0.08$ at $-50^{\circ} \mathrm{C}$. The cases with misfit strain $\varepsilon=0$ and $\varepsilon=2 \%$ differ in $S_{w, \text { th }}$ by $\sim 0.06$. An increase in $J_{s, \text { fr }}$ from $10^{-5} \mathrm{~s}^{-1}$ to $1 \mathrm{~s}^{-1}$ causes growth of $S_{w, \text { cr }}$ only by 0.01-0.02. We present here for comparison two previously derived threshold saturation ratios for homogeneous nucleation: Sassen and Dodd (1989, hereafter SD89) and Heymsfield and Miloshevich (1995, hereafter HM95). Figure 7 shows that our results are in qualitative agreement with these works, $S_{w, \text { th }}$ decreases with falling temperature; however, both SD89 and HM95 generally exceed these calculated values of $S_{w, \text { th }}$ with $\varepsilon=0$ and of $S_{w, \mathrm{cr}}$. These differences can be explained by (a) lower critical saturation ratios for heterogeneous nucleation than that for homogeneous nucleation illustrated also in Part II, and (b) residual supersaturation of $10 \%-20 \%$ that exists both in the parcel model SD89 and in natural cirrus measured by HM95. This residual ice supersaturation was found in simulation of cirrus and mixed clouds and discussed in detail in Khvorostyanov and Sassen (1998b,c, 2002), Gu and Liou (2000), Khvorostyanov et al. (2001, 2003), and Girard and Blanchet (2001) (note that the later data by Heymsfield et al. 1998 show lower average in-cloud $S_{w}$ in much better agreement with Fig. 7). The lower thresh- 
old humidity for heterogeneous nucleation than that for homogeneous nucleation was also described in the previous works (e.g., DeMott et al. 1994; Jensen et al. 1994; Kärcher et al. 1996; Sassen and Benson 2000). Figure 7 indicates that heterogeneous ice nucleation may occur in all types of clouds including cirrus.

It will be shown in Part II, that ice nucleation occurs mostly at $S_{w}$ close to $S_{w, \text { cr }}$. Using the data for $S_{w, \text { cr }}$ given in Fig. 7 we found a simple parameterization for $S_{w, \text { cr }}$,

$$
S_{w, \mathrm{cr}}=a_{\mathrm{sw}}+b_{\mathrm{sw}} T_{c}+c_{\mathrm{sw}} T_{c}^{2}
$$

where $T_{c}$ is the cloud temperature $\left({ }^{\circ} \mathrm{C}\right)$, and $a_{\mathrm{sw}}=1.12$, $b_{\mathrm{sw}}=1.12 \times 10^{-2}, c_{\mathrm{sw}}=9.6 \times 10^{-5}$, which is similar to both SD89 and HM95 for homogeneous nucleation. This equation approximates $S_{w, \text { cr }}$ shown in Fig. 7 with the error of less than $1 \%$ and can be used in large-scale models for parameterization of the critical saturation ratio for heterogeneous freezing that determines the onset of ice formation and is similar to the concept of the critical relative humidity for the onset of large-scale condensation (e.g., Slingo 1980).

\section{d. Critical and threshold temperature, freezing point depression, and effective temperature}

The critical temperature $T_{\text {cr }}$ of heterogeneous $\mathrm{CCN}$ freezing at any given $J_{s, \text { fr }}$ can be obtained by solving (2.1) for the critical energy as $\Delta F_{\text {cr }}=-k T \ln \left(J_{s, \mathrm{fr}} / C_{\mathrm{het}}\right)$ $-\Delta F_{\text {act }}$ and equating it to (2.10) (with $\alpha=0$ ):

$$
\begin{aligned}
T_{\mathrm{cr}}= & T_{0} S_{w}^{G} \exp \left[-\left(\frac{r_{\mathrm{sc}}}{r_{d}}+\frac{C_{\varepsilon} \varepsilon^{2}}{\rho_{i} L_{m}^{\mathrm{ef}}}\right)\right] \\
& \times \exp \left\{-\frac{1}{L_{m}^{\mathrm{ef}} \rho_{i}}\left[-\frac{16 \pi}{3} \frac{\sigma_{\mathrm{is}}^{2} f\left(m_{\mathrm{is}}, x\right)}{k T \ln \left(J_{s, \mathrm{fr}} / C_{\mathrm{het}}\right)+\Delta F_{\mathrm{act}}}\right]^{1 / 2}\right\} .
\end{aligned}
$$

For slow processes, when $J_{s, \mathrm{fr}} \rightarrow 0$, and In $J_{s, \mathrm{fr}} \rightarrow-\infty$, and neglecting the term with $r_{\mathrm{sc}} / r_{d}$, this equation is simplified and we obtain the threshold temperature

$$
T_{\text {th }}=T_{0} S_{w}^{G} \exp \left(-\frac{C_{\varepsilon} \varepsilon^{2}}{\rho_{i} L_{m}^{\mathrm{ef}}\left(T_{\mathrm{th}}\right)}\right) .
$$

Formally, this is a rather complicated nonlinear equation for $T_{\mathrm{th}}$. However, the temperature dependencies of $G(T)$ and $L_{m}^{\mathrm{ef}}(T)$ are relatively weak in the region of interest (e.g., $G=0.4$ at $T=-10^{\circ} \mathrm{C}$ and $G=0.43$ at $T=$ $-20^{\circ} \mathrm{C}$ ), and can be accounted for by iteration or neglected with a small error. For heterogeneous nucleation with $\varepsilon=0$, (3.12) can be simplified as

$$
T_{\text {th }}=T_{0} S_{w}^{G}=T_{0}\left(1+\delta_{w}\right)^{G} .
$$

Note that (3.13) holds also for homogeneous nucleation. The parameter $C_{\varepsilon}^{2} / \rho_{i} L_{m}^{\text {ef }} \ll 1$, and at small $\delta_{w} \ll 1$ we can expand (3.12) into the Taylor series by $\delta_{w}$ and by $C_{\varepsilon}^{2} / \rho_{i} L_{m}^{\text {ef }}$. Keeping only two first terms in $\delta_{w}$, we have

$$
\begin{aligned}
T_{\mathrm{th}} \approx & {\left[T_{0}+G T_{0} \delta_{w}+(1 / 2) G(G-1) \delta_{w}^{2}\right] } \\
& \times\left(1-C \varepsilon^{2} / \rho_{i} L_{m}^{\mathrm{ef}}\right)=T_{0}+\Delta T_{f}, \\
\Delta T_{f}= & \Delta T_{f 1}+\Delta T_{f 2}+\Delta T_{\varepsilon}, \\
\Delta T_{f 1}= & \frac{R_{v} T_{0}^{2}}{L_{m}} \delta_{w}, \quad \Delta T_{f 2}=\frac{R_{v} T_{0}^{2}}{2 L_{m}}\left(\frac{R_{v} T_{0}}{L_{m}}-1\right) \delta_{w}^{2}, \\
\Delta T_{\varepsilon}= & -T_{0} \frac{C \varepsilon^{2}}{\rho_{i} L_{m}^{\mathrm{ef}}},
\end{aligned}
$$

where (2.8) is incorporated for $G$, and $R_{v}$ is the specific gas constant for water vapor. Equations (3.14)-(3.16) describe the shift of the freezing point temperature in a solution drop due to the solute effects, where $\Delta T_{f 1}$ and $\Delta T_{f 2}$ denote corrections of the first and second order, respectively, and $\Delta T_{\varepsilon}$ is associated with the misfit strain effects of the insoluble substrate. It is easy to see that $\Delta T_{f 1}$ is equivalent to the traditional formulation for the freezing point depression $\Delta T_{f}$ in bulk water solution that is derived usually by equating chemical potentials of ice and solution (e.g., PK97; Curry and Webster 1999). The first term in expansion of $\Delta T_{f}$ by the mole fraction of a solute, $X_{s}=n_{s} / n_{\mathrm{H} 2 \mathrm{O}}$, can be written as (Curry and Webster 1999, p. 122)

$$
\Delta T_{f 1}=-\frac{R_{v} T_{0}^{2}}{L_{m}} X_{s} .
$$

In a dilute solution, $S_{w} \approx 1-X_{s}$, or $X_{s} \approx-\delta_{w}$, so the expressions for $\Delta T_{f 1}$ in both (3.16) and (3.17) are equivalent.

The freezing point depression is an important property of nucleating aerosols - their temperature threshold of nucleation. To estimate the effects of salt $\Delta T_{f 1}$ ("hygroscopic depression") and insoluble substrate $\Delta T_{\varepsilon}$ ("misfit depression"), note that $R_{v} T_{0}^{2} / L_{m} \approx 103 \mathrm{~K}$ and $\rho_{i} L_{m}^{\mathrm{ef}} \approx 3 \times 10^{9} \mathrm{erg} \mathrm{cm}^{-3}$, while $C \varepsilon^{2} \sim 1.7 \times 10^{7} \mathrm{erg}$ $\mathrm{cm}^{-3}$ at $\varepsilon=1 \%$ and $C \varepsilon^{2} \sim 6.8 \times 10^{7} \mathrm{erg} \mathrm{cm}^{-3}$ at $\varepsilon$ $=2 \%$. Since CCN serve in this freezing mode as IN, their equilibrium sizes and molalities can be easily calculated from Kohler theory. The mole fraction in each haze particle is adjusted to the environmental relative humidity to determine the freezing point depression (e.g., Khvorostyanov and Curry 1999b; Khvorostyanov and Sassen 1998a). For instance, at $S_{w}=0.9\left(\delta_{w}=\right.$ $-0.1)$ we obtain $\Delta T_{f 1}=103 \mathrm{~K} \times(-0.1)=-10.3 \mathrm{~K}$, and $\Delta T_{f 2}=-0.31 \mathrm{~K}$ is much smaller. The misfit depression is $\Delta T_{\varepsilon}=-1.55^{\circ} \mathrm{C}$ at $\varepsilon=1 \%$ and $\Delta T_{\varepsilon}=$ $-6.2^{\circ} \mathrm{C}$ at $\varepsilon=2 \%$. These simple estimates of $\Delta T_{\varepsilon}$ are in a good agreement with those in Young (1993). Equations (3.15) and (3.16) allow in addition their simple comparison with the freezing depression caused by the salts.

The effects of supersaturation on the ice nucleation rate from $\mathrm{CCN}$ can be characterized also by introducing the "effective supercooling" $\Delta T_{\text {ef }}$ and the "effective temperature" of nucleation $T_{\text {ef }}$ caused by supersatura- 
tion $\delta_{w}$ which can be defined using (2.7) from the relation

$$
\ln \left(T_{0} / T_{\text {ef }}\right)=\ln \left[\left(T_{0} / T\right) S_{w}^{G}\right] .
$$

Then, $T_{\text {ef }}$ and $\Delta T_{\text {ef }}$ can be defined as

$$
\begin{aligned}
T_{\mathrm{ef}} & =T S_{w}^{-G}=T\left(1+\delta_{w}\right)^{-G} \approx T+\Delta T_{\mathrm{ef}}, \\
\Delta T_{\mathrm{ef}} & =-T_{0} G \delta_{w}=-\frac{R_{v} T^{2}}{L_{m}^{\mathrm{ef}}} \delta_{w} .
\end{aligned}
$$

Since $G \sim 0.4$ at $T=-20^{\circ}$ to $0^{\circ} \mathrm{C}(\mathrm{KC} 00)$, the value of $\Delta T_{\text {ef }} \approx-100 \delta_{w}$, that is, $\Delta T_{\text {ef }}\left({ }^{\circ} \mathrm{C}\right)$ is approximately equal to water supersaturation (\%), but with the opposite sign. For example, the value of $\Delta T_{\text {ef }} \approx-5^{\circ} \mathrm{C}$ for $\delta_{w}=$ $0.05\left(S_{w}=.05\right)$, and $T_{\text {ef }} \approx-15^{\circ} \mathrm{C}$ for $T=-10^{\circ} \mathrm{C}$, which substantially increases nucleation rate. This can be a quantitative formulation of the Hobbs-Rangno effect (Hobbs and Rangno 1990; Rangno and Hobbs 1991) for high crystal production at relatively warm temperatures. Conversely, for $\delta_{w}=-0.05$, the value of $\Delta T_{\text {ef }}$ $\approx 5^{\circ} \mathrm{C}$ and $T_{\text {ef }} \approx-5^{\circ} \mathrm{C}$ for $T=-10^{\circ} \mathrm{C}$, with corresponding suppression of nucleation. Recall, these estimations are valid for freezing of deliquescent equilibrium $\mathrm{CCN}$ that may exist both at $\delta_{w}>0$ and $\delta_{w}<0$, but are not valid for drops.

\section{Nucleation in a polydisperse aerosol}

We have considered so far single aerosol particles characterized by the radius of insoluble substance $r_{N}$. An important feature of CCN in case 3 at $\delta_{w}>1$ considered in section $2 \mathrm{a}$ is that the equilibrium deliquescent interstitial CCN coexist with cloud drops. The nucleation rate in a polydisperse aerosol with uniform surface properties and size spectrum of the insoluble fraction $f_{a}\left(r_{N}\right)$ normalized to the total concentration $N_{a}$ can be found by averaging over aerosol size spectrum. Note that the size spectrum of the original dry $\mathrm{CCN}, f_{d}\left(r_{d 0}\right)$ transforms into the spectrum of the wet aerosol above the threshold of deliquescence of the soluble fraction and $\delta_{w}<0$, and into the spectrum of interstitial wet $\operatorname{CCN} f_{w}\left(r_{d}\right)$ at $\delta_{w}>0$, which is limited by the maximum radius $r_{b} \approx(2 / 3)\left(A_{\mathrm{sa}} / \delta_{w}\right)$ with $\delta_{w}$ in share of unit (e.g., Sedunov 1974; Khvorostyanov and Curry 1999a). At supersaturation, the droplets with radii $r_{d}>r_{b}$ are activated cloud drops, and those with $r_{d}<r_{b}$ are nonactivated $\mathrm{CCN}$ in equilibrium with supersaturated environment. Since $A_{\mathrm{sa}} \sim 10^{-1} \mu \mathrm{m}$ at the considered temperatures, the values of $r_{b}$ are $r_{b} \sim 1 \mu \mathrm{m}, 0.1 \mu \mathrm{m}$, and $0.01 \mu \mathrm{m}$ at $\delta_{w}=0.001,0.01$, and $0.1(0.1 \%-10 \%$, respectively). The value of $r_{b}$ determines the well-known gap between the CCN and cloud drop size spectra (e.g., PK97).

The probability of freezing of an aerosol particle containing insoluble part with $r_{N}$ is (PK97)

$$
P_{\mathrm{cf}}\left(r_{N}, t\right)=1-\exp \left[-\int_{0}^{t} J_{s, \mathrm{fr}}\left(r_{N}, t^{\prime}\right) d t^{\prime}\right] .
$$

The number of particles $d N_{\mathrm{cf}}$ nucleated from CCN by the deliquescence-freezing mode in the range $\left(r_{N}, r_{N}+\right.$ $\left.d r_{N}\right)$ is

$$
d N_{\mathrm{cf}}\left(r_{N}, t\right)=P_{\mathrm{cf}}\left(r_{N}, t\right) f_{a}\left(r_{N}\right) d r_{N},
$$

and the total number of nucleated particles is obtained by integrating over the aerosol size spectrum:

$$
\begin{aligned}
N_{\mathrm{fr}}(t) & =\int_{r_{\min }}^{r_{\max }} d N_{\mathrm{cf}}\left(r_{N}, t\right) f_{a}\left(r_{N}\right) d r_{N} \\
& =\int_{r_{\min }}^{r_{\max }} P_{\mathrm{cf}}\left(r_{N}, t\right) f_{a}\left(r_{N}\right) d r_{N} .
\end{aligned}
$$

The probability of freezing $P_{\text {cf }, p}$ in a polydisperse aerosol is then

$$
P_{\mathrm{cf}, p}(t)=\frac{N_{\mathrm{fr}}(t)}{N_{a}}=\frac{1}{N_{a}} \int_{r_{\min }}^{r_{\max }} P_{\mathrm{cf}}\left(r_{N}, t\right) f_{a}\left(r_{N}\right) d r_{N} .
$$

The crystal nucleation rate $\left(\mathrm{cm}^{-3} \mathrm{~s}^{-1}\right)$ in a polydisperse aerosol can be calculated as

$$
\begin{aligned}
R_{\mathrm{fr}}=\frac{d N_{\mathrm{fr}}}{d t}= & \int_{r_{\min }}^{r_{\max }} d r_{N} f_{a}\left(r_{N}\right) J_{s, \mathrm{fr}}(t) \\
& \times \exp \left[-\int_{0}^{t} J_{s, \mathrm{fr}}\left(t^{\prime}\right) d t^{\prime}\right] .
\end{aligned}
$$

The above equations include the radius $r_{N}$ of insoluble fraction but not the radius of the haze particles $r_{d}$. The reason for this is that the freezing rate in (2.1) depends on the surface area $\sim r_{N}^{2}$ of the insoluble inclusion inside a partially soluble CCN with $r_{N}$, but not on the surface $\sim r_{d}^{2}$ of the entire CCN particle. The radius $r_{d}$ increases during deliquescence of the $\mathrm{CCN}$, and can be expressed in equilibrium via the dry radius $r_{d 0}$ and some function of water saturation ratio $\psi\left(S_{w}\right)$ as $r_{d}\left(S_{w}\right)=r_{d 0} \psi\left(S_{w}\right)$ (e.g., Khvorostyanov and Curry 1999b). So, the CCN hygroscopic growth can be described by $S_{w}$; however, the effect of $S_{w}$ is already accounted for in expressions for $r_{\mathrm{cr}}$ and $\Delta F_{\mathrm{cr}}$ (2.7) and (2.10). Unfortunately, not much is known about the size distributions and properties of insoluble substance in CCN. We can estimate $f_{a}\left(r_{N}\right)$ using data on the mass soluble fraction of $\mathrm{CCN}$, which varies over the range $0.1-1.0$ with average value of 0.5 (PK97, chapter 8). As mentioned above, the radii $r_{d 0}$ and $r_{N}$ are related as $r_{N} \sim r_{d 0} \chi_{N}^{1 / 3}$, so that $r_{N}$ and $r_{d 0}$ are quite comparable for the mean (0.5) and especially for the high (0.9) fractions $\chi_{N}: r_{N} \sim 0.8 r_{d 0}$ for $\chi_{N}=0.5$ (as in the CSU model by DeMott et al. 1998) and $r_{N} \sim$ $0.97 r_{d 0}$ for $\chi_{N}=0.9$.

This means that the modal radii and dispersions of the size spectra of insoluble fraction $f_{a}\left(r_{N}\right)$ are rather close to the spectra of dry aerosol. This fact is used later for averaging over $r_{N}$ with $f_{a}\left(r_{N}\right)$, and we choose $f_{a}\left(r_{N}\right)$ in a first approximation as a lognormal distribution with the modal radius $r_{N, \bmod }=0.02 \mu \mathrm{m}$, and 


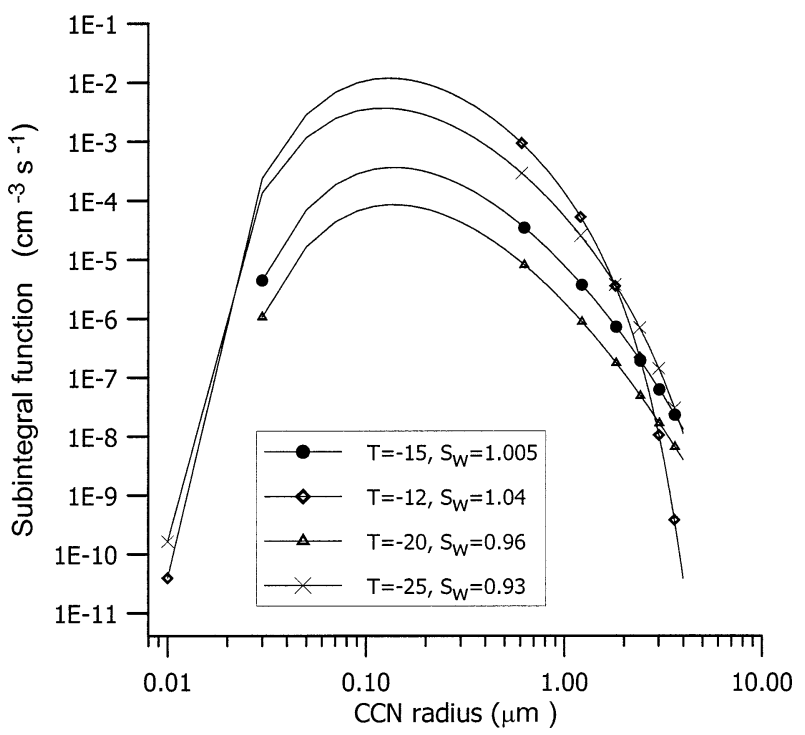

FIG. 8. Subintegral function $\left(\mathrm{cm}^{-3} \mathrm{~s}^{-1}\right)$ for the freezing nucleation rate $R_{\mathrm{fr}}$, which shows the contributions of the various aerosol radii into the freezing rate for four cases: $T=-15^{\circ} \mathrm{C}, S_{w}=1.005$ (circles); $T=-12^{\circ} \mathrm{C}, S_{w}=1.04$ (diamonds); $T=-20^{\circ} \mathrm{C}, S_{w}=0.96$ (triangles); $T=-25^{\circ} \mathrm{C}, S_{w}=0.93$ (crosses).

dispersion $\sigma_{N}=2.5$, which is typical of a continental aerosol (PK97; Seinfeld and Pandis 1998). It will be shown in Part II that this choice yields quite reasonable concentrations of nucleated crystals.

Figure 8 shows the subintegral function $\left(\mathrm{cm}^{-3} \mathrm{~s}^{-1}\right)$ for the freezing nucleation rate $R_{\mathrm{fr}}$ in (4.5) for various combinations of temperature and humidity. This figure illustrates that the main contribution to the freezing rate comes from the submicron aerosol mode, around 0.1$0.5 \mu \mathrm{m}$, and contributions from nucleation and giant modes are smaller. This finding is in agreement with the experimental data on the radii of IN in the central particles of snow crystals that were typically in the range 0.05-7.5 $\mu \mathrm{m}$ with a mode between 0.25 and $2.5 \mu \mathrm{m}$ (PK97), and with the recent measurements of IN in the Arctic that found modal radii $r_{m}$ of $0.18-0.23 \mu \mathrm{m}$ (Rogers et al. 2001), and in the central United States, $r_{m} \approx$ $0.2 \mu \mathrm{m}$ (Chen et al. 1998; Rogers et al. 1998). Note that we consider here only the simplest case of monomodal aerosol size spectrum and do not include the larger size fractions, which also may contribute to the freezing rate. The addition of larger aerosol particles should be the subject of the future studies along with the variation of insoluble fraction over the size spectrum, since the insoluble fraction of $\mathrm{CCN}$ increases with size faster than the soluble fraction (PK97), thereby increasing the catalyzing properties of large $\mathrm{CCN}$ in ice nucleation (Berezinsky and Stepanov 1986).

The aerosol size with maximum contribution to the nucleation rate $r_{N, \max }\left(T, S_{w}\right)$, illustrated in Fig. 8, can be estimated analytically using this theory. First, we perform some simplifications. Since typical values of $r_{\mathrm{cr}}$ are $10^{-3}-10^{-2} \mu \mathrm{m}$, for most aerosol particles with

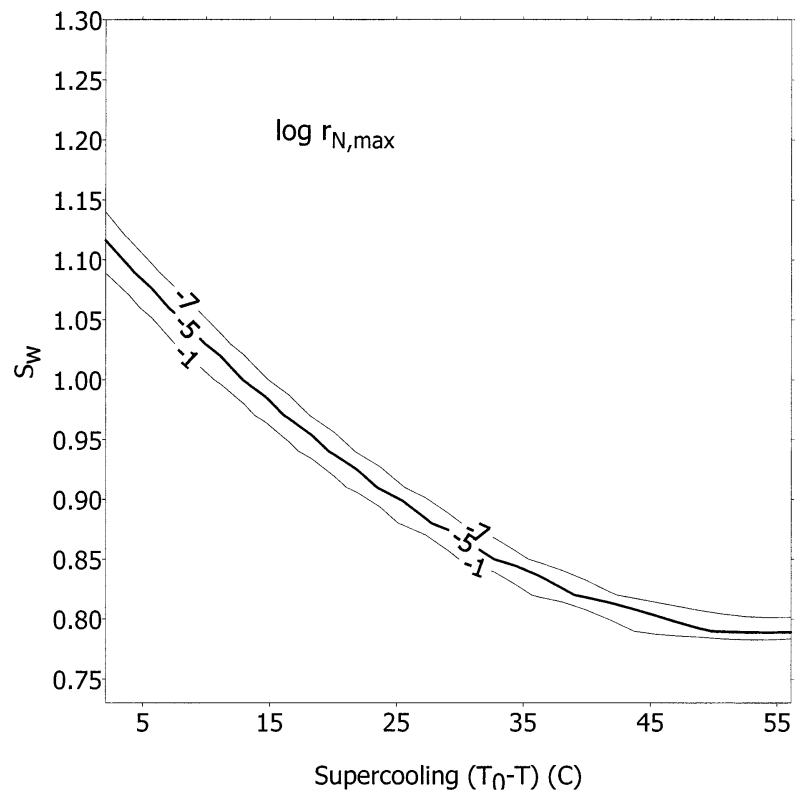

FIG. 9. Logarithm of the radius $r_{N}(\mathrm{~cm})$ of insoluble aerosol fraction with maximum heterogeneous freezing nucleation rate calculated with Eq. (3.6b); $\log =-1$ means $r_{N}=10^{-1} \mathrm{~cm}$ or $1000 \mu \mathrm{m}, \log =-5$ means $r_{N}=10^{-5} \mathrm{~cm}$ or $0.1 \mu \mathrm{m}$ (bold line), log $=-7$ means $r_{N}=$ $10^{-7} \mathrm{~cm}$. Aerosols in the size spectrum $r_{N}=0.01-100 \mu \mathrm{m}$ can preferably nucleate ice crystals in the narrow corridor of $T, S_{w}$.

$r_{N} \geq 0.1 \mu \mathrm{m}$, the parameter $x=r_{N} / r_{\text {cr }} \gg 1$. Then the geometrical factor $f\left(m_{\text {is }}, x\right)(2.11)$ is equal to its asymptotic value $f\left(m_{\text {is }}, x\right)=\left(m_{\text {is }}^{3}-3 m_{\text {is }}+2\right) / 4$ at $x \rightarrow$ $\infty$, and the nucleation rate per unit area $J_{S, \mathrm{fr}} / r_{N}^{2} \equiv y(T)$ does not depend on $r_{N}$ as it is seen from (2.1). Further, we assume that the aerosol is monodisperse with radius $r_{N}$. Then the nucleation rate $R_{\mathrm{fr}}$ in (4.5) can be presented as $R_{\mathrm{fr}}=y(T) r_{N}^{2} \exp \left[-y(T) r_{N}^{2} \Delta t\right]$, where $\Delta t$ is the time interval. This is a Gaussian distribution relative to $r_{N}$, and a gamma distribution relative to $y(T)$. Maxima are determined from the conditions $d R_{\mathrm{fr}} / d r_{N}=0$ for $r_{N}$ and $d R_{\mathrm{fr}} / d T=0$ for temperature. Both conditions lead to the equation

$$
y\left(T, S_{w}\right) r_{N, \max }^{2} \Delta t=1 .
$$

Thus, at some fixed $T$, we can calculate the radius of aerosol particles with maximum freezing rate:

$$
r_{N, \max }\left(T, S_{w}\right)=\left[y\left(T, S_{w}\right) \Delta t\right]^{-1 / 2} .
$$

This equation shows that ice nucleation initiates from the largest aerosol particles, and then the aerosol radius with maximum nucleation rate decreases with time. For $y(T) \sim 10^{8} \mathrm{~cm}^{-2} \mathrm{~s}^{-1}$ (see Fig. 6) and $\Delta t=0.01 \mathrm{~s}$, we have from (4.6b) $r_{N} \sim 10 \mu \mathrm{m}$; and $r_{N} \sim 0.1 \mu \mathrm{m}$ at $\Delta t$ $=100 \mathrm{~s}$.

A general picture of the aerosol radius $r_{N, \max }\left(T, S_{w}\right)$ with maximum contribution to the freezing rate calculated with (4.6b) and the same parameters as for $J_{s, \mathrm{fr}}$ in Fig. 6 is shown as a $T-S_{w}$ diagram in Fig. 9. Aerosols in the size range $r_{N}$ from 0.1 to a few tens of microns 
can preferably nucleate ice crystals in rather narrow range of $T, S_{w}$. The dominant aerosol radius decreases rapidly at fixed $T$ and increasing $S_{w}$, and more slowly at fixed $S_{w}$ and decreasing $T$. This behavior predicted by (4.6b) and illustrated in Fig. 9 is quite reasonable (the colder and more humid, the smaller fraction is nucleated), is in agreement with the chamber experiments (e.g., Berezinsky and Stepanov 1986), and may help to find experimentally the aerosol fractions with maximum nucleation rate under various conditions.

\section{Conclusions}

This paper examines in detail the heterogeneous ice nucleation by freezing of $\mathrm{CCN}$ called here deliquescence-heterogeneous freezing or DHF mode. Expressions for the ice germ critical radius $r_{\mathrm{cr}}$ and energy $\Delta F_{\mathrm{cr}}$ are derived for the DHF mode and for the cloud drop immersion freezing mode as functions that depend simultaneously on both temperature $T$ and water saturation ratio $S_{w}$. The new equations for $r_{\text {cr }}$ and $\Delta F_{\text {cr }}$ generalize previous expressions that include equations for freezing of pure water at $S_{w}=1$, Kelvin's equations at $T \sim T_{0}$ (the case of nucleation of a crystal from vapor as in deposition mode); equations for $r_{\mathrm{cr}}$ and $\Delta F_{\mathrm{cr}}$ given by Fletcher (1962) and Young (1993) with account for the misfit strain but at $S_{w}=1$; and equations for homogeneous nucleation at $S_{w}<1$ expressed by Dufour and Defay (1963) via molar fraction; by Jensen et al. (1994), Tabazadeh et al. (1997), and MacKenzie et al. (1998) via water activity, and by Khvorostyanov and Sassen (1998a) via $S_{w}$ (see appendix B).

Detailed calculations of $r_{\mathrm{cr}}$ and $\Delta F_{\mathrm{cr}}$ are presented on $T-S_{w}$ diagrams that illustrate rates of heterogeneous ice nucleation by $\mathrm{CCN}$ freezing over a wide range of temperatures and humidities, showing where nucleation is favored and prohibited. Simplified analytic expressions for the nucleation rate are obtained that allow its formulation as a product of function of temperature and a function of supersaturation. This representation is convenient both for numerical calculations and analytical estimations.

The main results of this study are summarized below.

1) A theoretical foundation is provided for the interaction between the temperature and supersaturation dependencies in ice nucleation process by heterogeneous freezing of deliquescent-mixed CCN, whereby the soluble fraction accumulates water from the environmental vapor and the insoluble fraction catalyzes ice nucleation. Corrections for solution and curvature are found to the classical nucleation theory of drop freezing, and they are combined together in a unified description.

2) Deliquescence freezing of $\mathrm{CCN}$ may occur under conditions of either subsaturation or supersaturation over water.

3) Deliquescence freezing of CCN may represent a sig- nificant fraction of ice nucleation. This is consistent with the recent measurements of ice nuclei that have frequently found soluble components and emphasized that the same mixed aerosol particles may serve as IN and CCN (e.g., Chen et al. 1998; DeMott et al. 1998; Rogers et al. 1998, 2001). The concepts presented here on heterogeneous ice nucleation for deliquescence-freezing mode are close to those developed by DeMott et al. (1998) and used in the International Cirrus Parcel Model Comparison Project (CPMCP; Lin et al. 2002).

4) This theory is used to develop a simple parameterization for the critical saturation ratio for heterogeneous nucleation as a function of cloud temperature that is suitable for use in large-scale models, analogous to the concept of critical relative humidity for the onset of large-scale condensation.

5) Analytical expressions are found for the critical and threshold temperatures of heterogeneous nucleation as the functions of saturation ratio for an arbitrary nucleation rate. A simple method is presented for estimating the freezing point shift and the contributions from the solution concentration and the misfit strain of insoluble substrate.

The approach described here can be considered as an approximation to a new quantitative theory of heterogeneous ice nucleation by freezing deliquescent mixed CCN that includes a unified description of temperature and humidity dependencies. The development here has been conducted for "static" conditions. Part II investigates this theory using a dynamical parcel model, so that the temporal evolution (kinetics) of heterogeneous ice nucleation can be explored using this theory.

Acknowledgments. This research has been supported by grants from the DOE Atmospheric Radiation Measurement Program and NASA CRYSTAL-FACE. We are grateful to three anonymous reviewers for their valuable remarks that greatly helped to clarify and improve the manuscript. Neville Fletcher, Gabor Vali, and Paul DeMott are thanked for the useful discussions and comments. The help of Jody Norman in preparation of the manuscript is gratefully acknowledged.

\section{APPENDIX A}

\section{List of Symbols}

$\begin{array}{ll}A_{\mathrm{sa}} & \text { The Kelvin's curvature parameter } \\ a_{w} & \text { The activity of water in solution } \\ B_{\mathrm{sa}} & \text { The term that describes the solution ef- } \\ & \text { fects in (2.4) and (4.6) } \\ C_{\mathrm{het}} & \begin{array}{l}\text { Preexponential factor in }(2.1) \\ c_{1 s}\end{array} \\ C_{\varepsilon} & \begin{array}{l}\text { Concentration of water molecules ad- } \\ \text { sorbed on } 1 \mathrm{~cm}^{-2} \text { of a surface }\end{array} \\ & \text { Constant in the term with elastic strain }\end{array}$


$\Delta F_{\mathrm{act}}$

Activation energy for diffusion across the liquid-ice boundary

$\Delta F_{\mathrm{cr}}, \Delta F_{c, \mathrm{dr}}$ Critical energies of ice germ formation for freezing and deposition modes

$f\left(m_{\text {is }}, x\right) \quad$ Geometric factor

$G \quad$ Dimensionless parameter defined in (2.8)

$H_{\mathrm{cs}} \quad$ Function defined in (2.4)

$h \quad$ Planck's constant

$J_{S \text {,fr }} \quad$ Rate of heterogeneous germ formation by

freezing

$J_{S \text {,dep }} \quad$ Deposition nucleation rate

$k \quad$ Boltzmann's constant

$L_{m} \quad$ Latent heat of melting

$L_{m}^{\text {ef }} \quad$ Effective latent heat of melting

$M_{s} \quad$ The molecular weight of soluble material of a nucleus

$M_{w} \quad$ Molecular weight of water

$m_{\text {is }}=\cos \theta_{\text {is }}$ Contact or wettability parameter at the solution-ice interface

$N_{\text {IN }} \quad$ The number concentration of IN

$d N_{f} / d t \quad$ Nucleation rate

$R, R_{v} \quad$ Universal gas constant and water vapor gas constant

$r_{b} \quad$ The boundary radius of deliquescent $\mathrm{CCN}$

$r_{\mathrm{cr}}, r_{\mathrm{cr}, d} \quad$ Critical radius of ice germ for freezing and deposition mode

$r_{d} \quad$ Radius of an aqueous solution droplet or cloud drop

$r_{N} \quad$ Radius of the curved insoluble substrate

$S_{w}, S_{i}$

$S_{w, \mathrm{th}}(T)$,

$S_{w, \mathrm{cr}}(T)$

$T$

$T_{\text {th }}, T_{\text {cr }}$

$T_{\text {ef }}, \Delta T_{\text {ef }}$

$X_{s}$

$\alpha$

$\chi_{m}$

$\delta_{w}, \delta_{i}$

$\varepsilon$

$\Phi_{s}$

$\nu$

$\theta_{\text {is }}$

$\rho_{i}, \rho_{w}$

$\rho_{N}$

$\rho_{v}$

$\rho_{\mathrm{ws}}, \rho_{\mathrm{is}}$

$\sigma_{s / a}, \sigma_{\text {is }}$

$\tau_{\text {eq }}$
Saturation ratios over water and ice Threshold and critical saturation ratios of heterogeneous $\mathrm{CCN}$ freezing

Temperature

Threshold and critical temperatures of heterogeneous $\mathrm{CCN}$ freezing

Effective temperature and effective supercooling of nucleation

Mole fraction of a solute

Fraction of surface with $m_{\text {is }}=1$

The mass fraction of soluble material of a nucleus

Supersaturations over water and ice

Elastic misfit strain

The osmotic coefficient

The number of ions in solution

The contact angle

Densities of ice and water

The density of the insoluble fraction

The vapor density

Saturated vapor densities over water and ice

Surface tensions at solution-air and solution-ice interfaces

Relaxation time during which deliquescent $\mathrm{CCN}$ reach equilibrium with environment
Relaxation time during which salt concentration within a CCN drop reaches equilibrium

\section{APPENDIX B}

\section{Comparison of Various Expressions for the Critical Radius of an Ice Germ}

We consider here various particular cases of (2.7) for $r_{\mathrm{cr}}$.

1) The simplest case with $\varepsilon=0$ (no misfit strain), $a$ bulk solution $\left(1 / r_{d}=0\right.$ ), and $S_{w}=1$ (pure water and no external sources of supersaturation). Equation (2.7) is simplified as

$$
r_{\text {cr }}=2 \sigma_{\text {iw }} /\left[\rho_{i} L_{m}^{\mathrm{ef}} \ln \left(T_{0} / T\right)\right],
$$

where $\sigma_{\text {iw }}$ is the surface tension at the ice-water interface. This equation is often written as

$$
r_{\mathrm{cr}}=2 \sigma_{\mathrm{iw}} /\left[N_{i} k T \ln \left(e_{\mathrm{sw}} / e_{\mathrm{si}}\right)\right]
$$

where $N_{i}$ is the concentration of molecules per unit volume in ice, $e_{\mathrm{sw}}$, and $e_{\mathrm{si}}$ are the saturated vapor pressures over water and ice [e.g., Young (1993), and equivalent Fletcher's (1962) expressions for $\Delta F_{\text {cr }}$ ]. To simplify further comparison, we need to show the equivalence of (B.1) and (B.2). This can be done by using Clausius-Clapeyron equation for $e_{\mathrm{sw}}$ and $e_{\mathrm{si}}$ :

$d\left(\ln e_{\mathrm{sw}}\right) d T=L_{e} / R_{v} T^{2}, \quad d\left(\ln e_{\mathrm{si}}\right) d T=L_{s} / R_{v} T^{2}$,

where $L_{e}$ and $L_{s}$ are the specific heats of evaporation and deposition. Subtracting these equations, integrating from $T$ to $T_{0}$, using the relations $e_{\mathrm{sw}}=e_{\mathrm{si}}$ at $T=T_{0}$, and $L_{s}-L_{e}=L_{m}$, we obtain

$$
\ln \left(e_{\mathrm{sw}} / e_{\mathrm{si}}\right) \approx L_{m} \Delta T /\left(R_{v} T_{0}^{2}\right),
$$

where $\Delta T=T_{0}-T$. Substituting (B.4) into (B.2) and using the relation $N_{i}=N_{A} / v_{\text {io }}=N_{A} \rho_{i} / M_{w}$, with $N_{A}$ and $v_{\text {io }}$ being the Avogadro's number and molar ice volume, the denominator in (B.2) can be rewritten as

$$
N_{i} k T \ln \left(e_{\mathrm{sw}} / e_{\mathrm{si}}\right) \approx \rho_{i} L_{m} \Delta T / T_{0} .
$$

The denominator in (B.1) can be rewritten for a not very large supercooling as

$$
\rho_{i} L_{m}^{\mathrm{ef}} \ln \left(T_{0} / T\right) \approx \rho_{i} L_{m} \Delta T / T_{0},
$$

which coincides with (B.5). Thus Eqs. (B.1) and (B.2) for $r_{\text {cr }}$ are equivalent for $\Delta T \ll T_{0}$.

2) Misfit strain is accounted for, $\varepsilon \neq 0$, but $S_{w}=1$. Equation (2.7) becomes

$$
r_{\mathrm{cr}}=2 \sigma_{\mathrm{iw}} /\left[\rho_{i} L_{m}^{\mathrm{ef}} \ln \left(T_{0} / T\right)\right]-C_{\varepsilon} \varepsilon^{2} .
$$

This expression can be compared to Fletcher's (1962) formulation for $\Delta F_{\text {cr }}$

$$
r_{\mathrm{cr}}=2 \sigma_{\mathrm{iw}} /\left[N_{i} k T \ln \left(e_{\mathrm{sw}} / e_{\mathrm{si}}\right)\right]-C_{\varepsilon} \varepsilon^{2} .
$$


Equivalence of (B.7) and (B.8) becomes apparent by accounting for (B.5) and (B.6). Equation (B.7) also yields directly the equation for $\Delta F_{\text {cr }}$ given in PK97 (p. 344).

3) Parameters $\varepsilon=0, r_{\mathrm{sc}} \ll r_{d}$, and $S_{w}<1$. We have from (2.7),

$$
\begin{aligned}
r_{\mathrm{cr}} & =\frac{2 \sigma_{\mathrm{is}}}{\left[\rho_{i} L_{m}^{\mathrm{ef}} \ln \left(T_{0} / T\right) S_{w}^{G}\right]} \\
& =\frac{2 \sigma_{i / s}}{\rho_{i} L_{m}^{\mathrm{ef}}(T)\left(\ln T_{0} / T\right)+\rho_{i}\left(R / M_{w}\right) T \ln S_{w}} .
\end{aligned}
$$

This equation is similar to that derived for homogeneous nucleation by Dufour and Defay (1963) in terms of molar fraction, by Jensen et al. (1994), Tabazadeh et al. (1997), and MacKenzie et al. (1998) in terms of water activity if $a_{w} \approx S_{w}$ for $S_{w}<1$, and coincides with that from Khvorostyanov and Sassen (1998a, 2002).

4) Parameters $\varepsilon=0, r_{\mathrm{sc}} \ll r_{d}$, and $T \rightarrow T_{0}$, or $\mid 1-$ $T_{0} / T|\ll| 1-S_{w} \mid$ (temperature is much closer to $T_{0}$ than $S_{w}$ to 1 ). Equation (2.7) converts into

$$
r_{\mathrm{cr}}=2 M_{w} \sigma_{\mathrm{is}} /\left[R T \rho_{i} \ln S_{w}\right],
$$

and resembles Kelvin's expression $r_{\mathrm{cr}}=2 M_{w} \sigma_{\mathrm{iv}} /$ $\left[R T \rho_{i} \ln S_{w}\right]$, for the nucleation of a crystal from the vapor except that it contains $\sigma_{\text {is }}$ instead of $\sigma_{\text {iv }}$ for nucleation from the vapor. Since $\sigma_{\text {is }} \approx(1 / 4) \sigma_{\text {iv }}$, comparison of these two equations show that ice germ formation by freezing mode is energetically much easier than from the vapor by deposition mode.

5) Parameter $S_{w}>1$. This is a new case that describes both heterogeneous $(\varepsilon \neq 0)$ and homogeneous $(\varepsilon=$ 0 ) freezing of $\mathrm{CCN}$ at supersaturations as described in the text.

So, (2.7) generalizes and unifies all these particular cases for the critical germ radius.

\section{REFERENCES}

Berezinsky, N. A., and G. V. Stepanov, 1986: Dependence of natural ice-forming nuclei concentration of different size on the temperature and supersaturation. Izv. Acad Sci. USSR, Atmos. Oceanic Phys., 22, 722-727.

Chen, Y., S. M. Kreidenweis, L. M. McInnes, D. C. Rogers, and P. J. DeMott, 1998: Single particle analyses of ice nucleating aerosols in the upper troposphere and lower stratosphere. Geophys. Res. Lett., 25, 1391-1394.

Cotton, W. R., G. J. Tripoli, R. M., Rauber, and E. A. Mulvihill, 1986: Numerical simulation of the effects of varying ice nucleation rates and aggregation process on orographic snowfall. J. Climate Appl. Meteor., 25, 1658-1680.

Curry, J. A., and P. Webster, 1999: Thermodynamics of Atmospheres and Oceans. Academic Press, $471 \mathrm{pp}$.

—, W. B. Rossow, D. Randall, and J. L. Schramm, 1996: Overview of Arctic cloud and radiation properties. J. Climate, 9, 17311764.

Defay, R., I. Prigogine, and A. Bellemans, 1966: Surface Tension and Absorption. Wiley, $432 \mathrm{pp}$.

DeMott, P. J., 2002: Laboratory studies of cirrus cloud processes. Cirrus, D. Lynch et al., Eds., Oxford University Press, 102-135.
— M. P. Meyers, and W. R. Cotton, 1994: Parameterization and impact of ice initiation processes relevant to numerical model simulation of cirrus clouds. J. Atmos. Sci., 51, 77-90.

— D. D. Rogers, and S. M. Kreidenweis, 1997: The susceptibility of ice formation in upper tropospheric clouds to insoluble aerosol components. J. Geophys. Res., 102, 19 575-19 584.

,,--- , Y. Chen, C. H. Twohy, D. Baumgardner, A. J. Heymsfield, and K. R. Chan, 1998: The role of heterogeneous freezing nucleation in upper tropospheric clouds: Inferences from SUCCESS. Geophys. Res. Lett., 25, 1387-1390.

Djikaev, Y. S., A. Tabazadeh, P. Hamill, and H. Reiss, 2002: Thermodynamic conditions for the surface-stimulated crystallization of atmospheric droplets. J. Phys. Chem., A106, 10 247-10 253.

Dufour, L., and R. Defay, 1963: Thermodynamics of Clouds. Academic Press, $255 \mathrm{pp}$.

Fletcher, N. H., 1962: The Physics of Rainclouds. Cambridge University Press, $390 \mathrm{pp}$.

, 1969: Active sites and ice crystal nucleation. J. Atmos. Sci., 26, 1266-1278.

Fukuta, N., and R. C. Schaller, 1982: Ice nucleation by aerosol particles: Theory of condensation-freezing nucleation. J. Atmos. Sci., 39, 648-655.

Girard, E., and J.-P. Blanchet, 2001: Simulation of Arctic diamond dust, ice fog, and thin stratus using an explicit aerosol-cloud model. J. Atmos. Sci., 58, 1199-1221.

$\mathrm{Gu}$, Y., and K. N. Liou, 2000: Interactions of radiation, microphysics, and turbulence in the evolution of cirrus clouds. J. Atmos. Sci., 57, 2463-2479.

Hänel, G., 1976: The properties of atmospheric aerosol particles as functions of the relative humidity at thermodynamic equilibrium with the surrounding moist air. Advances in Geophysics, Vol. 19, Academic Press, 74-183.

Heymsfield, A. J., and R. M. Sabin, 1989: Cirrus crystal nucleation by homogeneous freezing of solution droplets. J. Atmos. Sci., 46, 2252-2264.

— ature influences on cirrus formation and evolution: Observations from wave clouds and FIRE II. J. Atmos. Sci., 52, 4302-4303.

—_ — - C. Twohy, G. Sachse, and S. Oltmans, 1998: Upper tropospheric relative humidity observations and implications for cirrus ice nucleation. Geophys. Res. Lett., 25, 1343-1347.

Hobbs, P. V., and A. L. Rangno, 1990: Rapid development of high ice particle concentrations in small polar maritime cumuliform cloud. J. Atmos. Sci., 47, 2710-2722.

Huffman, P. J., 1973: Supersaturation spectra of AgI and natural ice nuclei. J. Appl. Meteor., 12, 1080-1082.

Jeffery, C. A., and P. H. Austin, 1997: Homogeneous nucleation of supercooled water: Results from a new equation of state. J. Geophys. Res., 102 (D21), 25 269-25 279.

Jensen, E. J., O. B. Toon, D. L. Westphal, S. Kinne, and A. J. Heymsfield, 1994: Microphysical modeling of cirrus. 1. Comparison with 1986 FIRE IFO measurements. J. Geophys. Res., 99, $10421-10442$.

Kärcher, B., T. Peter, U. M. Biermann, and U. Schumann, 1996: The initial composition of jet condensation trails. J. Atmos. Sci., 53, 3066-3083.

Khvorostyanov, V., and K. Sassen, 1998a: Towards the theory of homogeneous nucleation and its parameterization for cloud models. Geophys. Res. Lett., 25, 3155-3158.

$\ldots$, and $-1998 \mathrm{~b}$ : Cirrus cloud simulation using explicit microphysics and radiation. Part I: Model description. J. Atmos. Sci., 55, 1808-1821.

- , and —-1998c: Cirrus cloud simulation using explicit microphysics and radiation. Part II: Microphysics, vapor and ice mass budgets, and optical and radiative properties. J. Atmos. Sci., 55, 1822-1845.

—_ and J. A. Curry, 1999a: A simple analytical model of aerosol properties with account for hygroscopic growth. Part I. Equilibrium size spectra and $\mathrm{CCN}$ activity spectra. J. Geophys. Res., 104, 2163-2174.

, and _ - 1999b: A simple analytical model of aerosol prop- 
erties with account for hygroscopic growth. Part II. Scattering and absorption coefficients. J. Geophys. Res., 104, 2175-2184.

- , and - 2000: A new theory of heterogeneous nucleation for application in cloud and climate models. Geophys. Res. Lett., 27, 4081-4084.

—, and K. Sassen, 2002: Microphysical processes in cirrus and their impact on radiation: A mesoscale modeling perspective. Cirrus, D. Lynch et al., Eds., Oxford University Press, 397-432.

— erogeneous freezing of deliquescent mixed CCN. Part II: Parcel model simulation. J. Atmos. Sci., in press.

- - - J. O. Pinto, M. Shupe, B. Baker, and K. Sassen, 2001: Modeling with explicit spectral water and ice microphysics of a two-layer cloud system of altostratus and cirrus observed during the FIRE Arctic Clouds Experiment. J. Geophys. Res., 106, 15 099-15 112.

I. Gultepe, and K. Strawbridge, 2003: A springtime cloud over the Beaufort Sea polynya: 3D simulation with explicit spectral microphysics and comparison with observations. J. Geophys. Res., 108, 4296, doi:10.1029/2001JD001489.

Lin, R.-F., D. O'C. Starr, P. J. DeMott, R. Cotton, K. Sassen, E. Jensen, B. Kärcher, and X. Liu, 2002: Cirrus parcel model comparison project. Phase I: The critical components to simulate cirrus initiation explicitly. J. Atmos. Sci., 59, 2305-2329.

MacKenzie, A. R., A. Laaksonen, E. Batris, and M. Kulmala, 1998 The Turnbull correlation and the freezing of stratospheric aerosol droplets. J. Geophys. Res., 103, 10 875-10 884.

Meyers, M. P., P. J. DeMott, and W. R. Cotton, 1992: New primary ice-nucleation parameterizations in an explicit cloud model. $J$ Appl. Meteor., 31, 708-721.

Pruppacher, H. R., and J. D. Klett, 1997: Microphysics of Clouds and Precipitation. 2d ed. Kluwer, 997 pp.

Rangno, A. L., and P. V. Hobbs, 1991: Ice particle concentrations and precipitation development in small polar maritime cumuliform clouds. Quart. J. Roy. Meteor. Soc., 117, 207-241.
— , and ——, 2001: Ice particles in stratiform clouds in the Arctic and possible mechanisms for the production of high ice concentrations. J. Geophys. Res., 106 (D14), 15 065-15 075.

Rogers, D. C., P. J. DeMott, S. M. Kreidenweis, and Y. Chen, 1998: Measurements of ice nucleating aerosols during SUCCESS. Geophys. Res. Lett., 25, 1383-1386.

,$- \ldots$, and,- 2001 : Airborne measurements of tropospheric ice-nucleating aerosol particles in the Arctic spring. J. Geophys. Res., 106, 15 053-15063.

Sassen, K., and G. C. Dodd, 1988: Homogeneous nucleation rate for highly supercooled cirrus cloud droplets. J. Atmos. Sci., 45, $1357-1369$.

—_ and _ 1989: Haze particle nucleation simulation in cirrus clouds, and application for numerical and lidar studies. J. Atmos. Sci., 46, 3005-3014.

study of the homogeneous and heterogeneous nucleation modes. Geophys. Res. Lett., 27, 521-524.

Sedunov, Y. S., 1974: Physics of Drop Formation in the Atmosphere. Wiley, $234 \mathrm{pp}$.

Seinfeld, J. H., and S. N. Pandis, 1998: Atmospheric Chemistry and Physics. Wiley, $1326 \mathrm{pp}$.

Slingo, J. M., 1980. A cloud parameterization scheme derived from GATE data for use with a numerical model. Quart. J. Roy. Meteor. Soc., 106, 747-770.

Tabazadeh, A., E. J. Jensen, and O. B. Toon, 1997: A model description for cirrus cloud nucleation from homogeneous freezing of sulfate aerosols. J. Geophys. Res., 102, 23 845-23 850.

_ supercooled water in clouds. Proc. Natl. Acad. Sci., 99, 15873 15878 .

Turnbull, D., and B. Vonnegut, 1952: Nucleation catalysis. Industr. Eng. Chem., 44, 1292.

Vali, G., 1985: Nucleation terminology. J. Aerosol Sci., 16, 575-576.

Young, K., 1993: Microphysical Processes in Clouds. Oxford University Press, 427 pp. 
Copyright of Journal of the Atmospheric Sciences is the property of American Meteorological Society and its content may not be copied or emailed to multiple sites or posted to a listserv without the copyright holder's express written permission. However, users may print, download, or email articles for individual use. 